\title{
The Human Gastric Pathogen Helicobacter pylori and Its Association with Gastric Cancer and Ulcer Disease
}

\author{
Bianca Bauer and Thomas F. Meyer \\ Department of Molecular Biology, Max Planck Institute for Infection Biology, Campus Charité Mitte, Charitéplatz 1, \\ 10117 Berlin, Germany \\ Correspondence should be addressed to Bianca Bauer, bauer@mpiib-berlin.mpg.de
}

Received 8 October 2010; Accepted 25 April 2011

Academic Editor: Hajime Kuwayama

Copyright (๑) 2011 B. Bauer and T. F. Meyer. This is an open access article distributed under the Creative Commons Attribution License, which permits unrestricted use, distribution, and reproduction in any medium, provided the original work is properly cited.

\begin{abstract}
With the momentous discovery in the 1980's that a bacterium, Helicobacter pylori, can cause peptic ulcer disease and gastric cancer, antibiotic therapies and prophylactic measures have been successful, only in part, in reducing the global burden of these diseases. To date, $\sim 700,000$ deaths worldwide are still attributable annually to gastric cancer alone. Here, we review $H$. pylori's contribution to the epidemiology and histopathology of both gastric cancer and peptic ulcer disease. Furthermore, we examine the host-pathogen relationship and $H$. pylori biology in context of these diseases, focusing on strain differences, virulence factors (CagA and VacA), immune activation and the challenges posed by resistance to existing therapies. We consider also the important role of hostgenetic variants, for example, in inflammatory response genes, in determining infection outcome and the role of $H$. pylori in other pathologies—some accepted, for example, MALT lymphoma, and others more controversial, for example, idiopathic thrombocytic purpura. More recently, intriguing suggestions that H. pylori has protective effects in GERD and autoimmune diseases, such as asthma, have gained momentum. Therefore, we consider the basis for these suggestions and discuss the potential impact for future therapeutic rationales.
\end{abstract}

\section{Introduction}

After a long history of discoveries on the pathology and bacterial colonization of the gastric mucosa starting in the beginning of the last century [1], the gastroenterologist Barry Marshall and the pathologist Robin Warren, in the 1980 's, fulfilled Koch's postulates for the association between gastritis and the human gastric pathogen Helicobacter pylori [1-3]. This decisive demonstration substantially changed our views of the microbiology and pathology of the human stomach and resulted in Marshall and Warren receiving the 2005 Nobel Prize in Physiology and Medicine.

Marshall and Warren's discovery founded the concept that infection with $H$. pylori, and not (if at all, very indirectly) stress, can lead to a variety of upper gastrointestinal disorders (Figure 1) such as gastric inflammation (gastritis), peptic ulcer disease $(10 \%-20 \%)$, distal gastric adenocarcinoma ( $1 \%-2 \%)$, and gastric mucosal-associated lymphoid tissue (MALT) lymphoma $(<1 \%)[4-7]$. These insights not only dramatically improved the management and therapy of gastric diseases but also provided an invaluable key for deeper insights into the pathogenesis of chronic infections. Moreover, during the past 20 years of research, the initially tentative association between persistent $H$. pylori infection and the development of gastric cancer has been well established [8-10], prompting the International Agency for Research on Cancer to classify H. pylori as a type I carcinogen [11].

While the prevalence of $H$. pylori is decreasing in the Western world, it still constitutes a significant medical burden in less industrialized countries, with constant higher infection rates and a more widespread distribution. The challenge now is to fill in the remaining gaps in our knowledge such as transmission routes as well as genetic preconditions and, as antibiotic resistance increases, develop preventative strategies, including improved hygiene conditions and vaccination.

Here, we review the role of $H$. pylori in severe human gastric disease such as peptic disease and gastric cancer, with an emphasis on clinical aspects and molecular pathogenesis. 


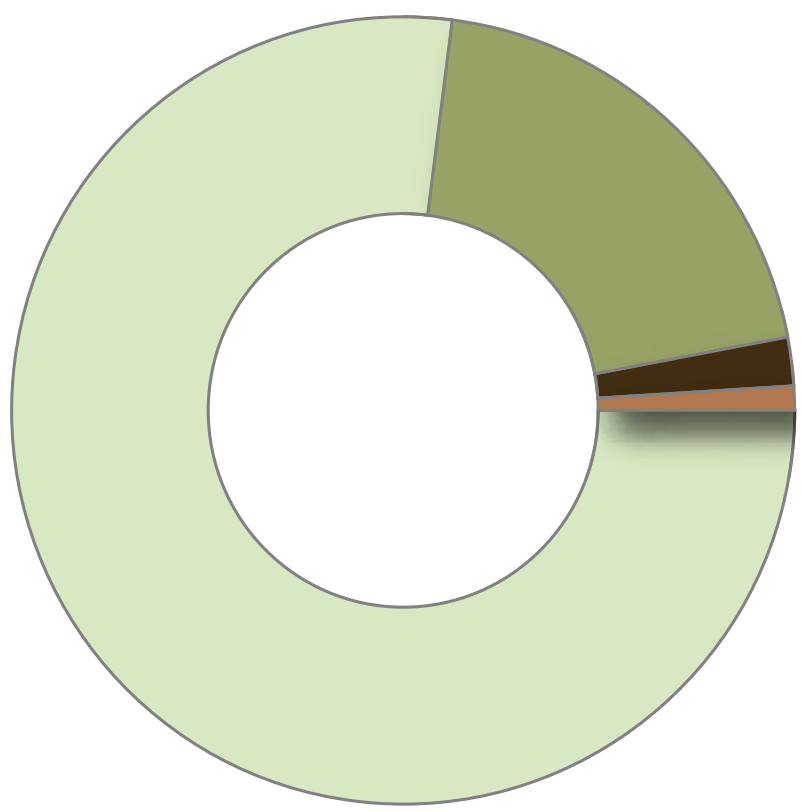

Gastritis (no overt disease)

Peptic ulcer $(10 \%-20 \%)$

Gastric cancer (1\%-2\%)

MALT lymphoma $(<1 \%)$

FIgURE 1: Frequency of $H$. pylori-associated human disease. All H. pylori-infected individuals develop gastric inflammation (gastritis). $10-20 \%$ develop peptic ulcers, whereas gastric cancer occurs in $1-2 \%$ of cases. A minority develop MALT lymphoma $(<1 \%)$.

\section{Evolution and Epidemiology}

The relationship between $H$. pylori and the human race began around 100,000 years ago. Phylogenetic simulations predict that the bacterium spread from East Africa over the same time scale as anatomically modern humans. The close association is underlined by observations showing that key patterns of bacterial genetic diversity are mirrored in the migration and ethnic origins of the human host [12]. By genotyping different strains collected from all over the world, the migration of humans into North America and the Pacific Area has been tracked $[13,14]$. Because a variety of gastric Helicobacter species can also be found in mammals besides humans [15], it is speculated that Helicobacter species are, in general, ancestral in mammals, and we may have already been infected by ancestors of the present $H$. pylori strains prior to our evolution towards modern mankind [16].

\section{Prevalence}

It is estimated that half of the world's population is infected with $H$. pylori; however, infection prevalence shows large geographical variations (Figure 2). For example, in several emerging nations and developing countries including India, Saudi Arabia, and Vietnam, more than $80 \%$ of the human population is infected. Infections in these regions are characterized by rapid acquisition even at a young age [17-19]. By contrast, the prevalence of $H$. pylori in industrialized countries is generally less than $40 \%$ and considerably lower in children than in adults [20]. H. pylori acquisition most frequently appears during early childhood [21], indicating that the decreased prevalence with age is largely due to a birth cohort effect rather than to new infections. The prevalence of $H$. pylori is inversely correlated with socioeconomic status, in particular in relation to family income levels, hygiene, and housing conditions [22]. This may be the reason why the prevalence of $H$. pylori in the industrialized world is significantly declining, whereas infection rates in developing countries remain relatively constant. Moreover, the widespread use of antibiotics may have accelerated the progressive decrease of $H$. pylori infection during childhood in developed countries. The elimination of $H$. pylori from the population by improved hygiene, housing conditions, and antibiotic treatment also strongly correlates with a decrease in gastric cancer worldwide [23].

\section{Transmission}

Although the association between $H$. pylori and severe human disease has been established, the exact mechanisms of $H$. pylori acquisition are still unknown (Figure 3). Gastrooral (e.g., exposure to vomit) and fecal-oral routes from human to human are posited as the primary means of transmission [21]. Indeed, H. pylori isolates from children and their mothers often have the same genotype [24, 25], supporting the notion that infection primarily occurs during childhood via close contact to family members (e.g., via premastication of food by parents). Other transmission routes, including exposure to contaminated food or water [26-28] or via domestic animals such as cats and sheep $[29,30]$ are also thought to play a role. To date, no conclusive evidence of predominant transmission by any of these routes has been established.

\section{Colonization and Persistence}

The majority of colonizing $H$.pylori reside within the gastric mucus and do not directly interact with host cells. Although $H$. pylori was long considered to be an extracellular bacterium, recent studies have provided evidence that H. pylori occasionally enters epithelial cells via a zipper-like mechanism [31-35]. Despite causing numerous gastric environmental changes and eliciting a host immune response, $H$. pylori can persistently colonize the human stomach for long periods [36]. This is in stark contrast to most other commonly ingested microbes, which cannot successfully colonize the stomach due to its manifold microbicidal properties.

\section{Mechanisms to Escape Low pH}

One of the most efficient biological barriers against bacterial infection is the acidic $\mathrm{pH}(<2)$ of the gastric lumen. However, the mucus layer overlying gastric epithelial cells exhibits a $\mathrm{pH}$ gradient, ranging from about $\mathrm{pH} 2$ at the luminal surface to between 5 and 6 at the epithelial surface [37]. 


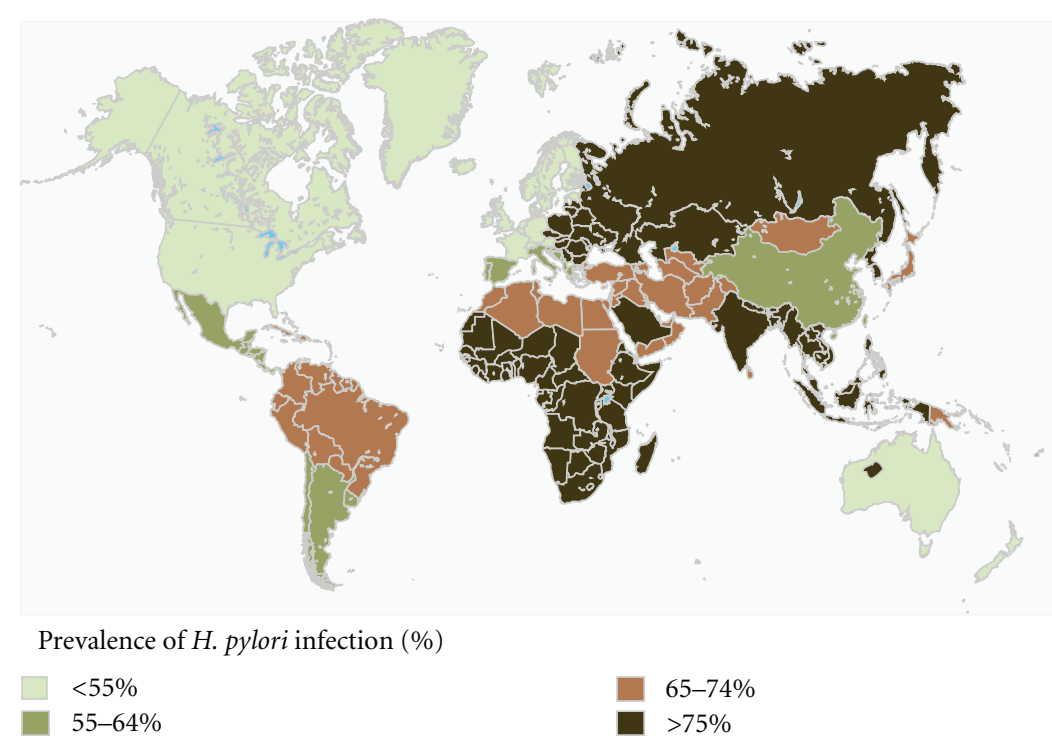

Figure 2: Worldwide prevalence of $H$. pylori infection. Infection rates in percent. H. pylori infection is highly prevalent in Africa, Asia, and South America.

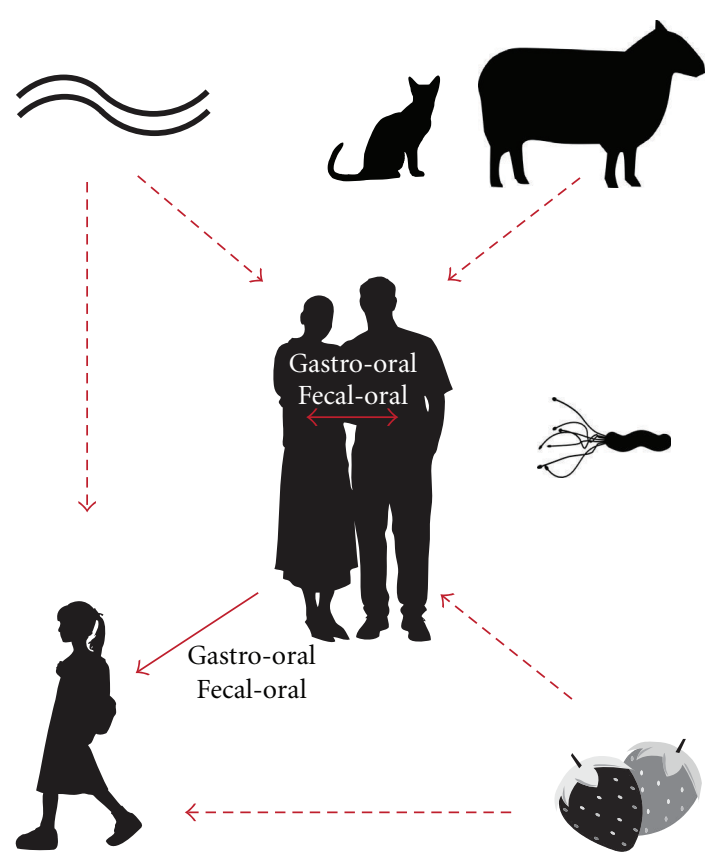

Figure 3: H. pylori transmission routes. Exact transmission routes are still not known. Person-to-person transmission by either the gastro-oral or fecal-oral route is most likely. Several studies indicate transmission via water, pets and food, but the majority of the data support the hypothesis that infection primarily occurs during childhood via close contact to family members especially from mother to child.

To avoid the bactericidal activity of acid, $H$. pylori produces substantial amounts of cytosolic and cell surface-associated urease. Urease is highly conserved in different H. pylori strains and transiently buffers the acidic environment by converting urea into ammonia and carbon dioxide $[18,38]$. H. pylori has evolved several other strategies to minimize exposure to the low $\mathrm{pH}$ in the gastric lumen (see Figure 4). The bacteria remain within the mucus in close proximity to the epithelial surface where the $\mathrm{pH}$ is nearly neutral. The spiral cell shape of Helicobacter, which is based on specific cross-linkages of the peptidoglycan layer, supports a screwlike movement which facilitates motility within the viscous mucus layer and enhances colonization efficiency $[39,40]$. To rapidly reach and remain in the mucus layer, $H$. pylori uses polar flagella $[41,42]$. Interestingly, null mutants defective in the production of flagella are unable to colonize gnotobiotic piglets but grow normally in vitro [43]. Consistent with the importance of functional flagella, control of directed movement by chemotactic responses is also essential for successful colonization [44]. Intriguingly, during infection of Mongolian gerbils $H$. pylori orient themselves via the $\mathrm{pH}$ gradient in the mucus, remaining mainly within $25 \mu \mathrm{m}$ of the epithelial surface and thereby avoiding acidic distal regions [45]. A specific chemoreceptor, encoded by the $\operatorname{tlp} B$ gene, seems to be involved as mutants can swim but do not avoid acidic regions [46].

\section{Adhesion to Epithelial Cells}

Only $\sim 20 \%$ of $H$. pylori present in the gastric mucosa are adhered to the surface of epithelial cells with a majority exhibiting a tropism for intercellular junctions and, occasionally, for deeper intercellular spaces $[47,48]$. Adherence is mediated by a subset of $H$. pylori-encoded autotransporter proteins (e.g., BabA, SabA, AlpA, AlpB, HopZ, and OipA) exposed on the bacterial cell surface. However, no individual molecule has been shown to be essential, indicating redundancy of adhesive mechanisms [49-52]. Additionally, expression of individual adhesins differs between strains and is variable within a single strain over time, leading to dynamic adaption capacities via on/off switching of gene expression, gene inactivation, or recombination [53-55]. 


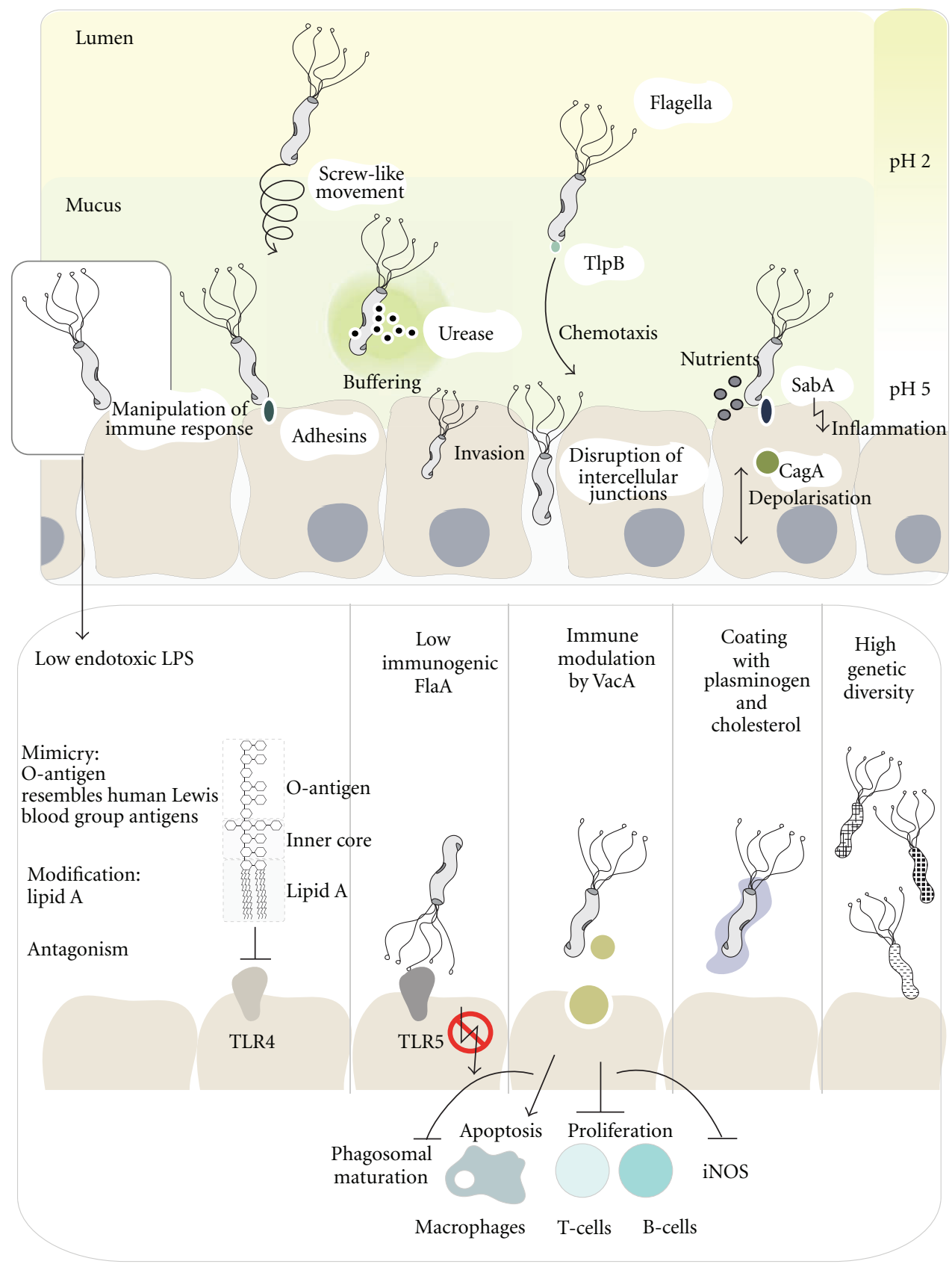

Figure 4: Molecular mechanisms of bacterial colonization and persistence. H. pylori has evolved numerous strategies to facilitate colonization and persistence in the hostile environment of the human stomach. Multiple polar flagella allow fast motility. Using the flagella, the bacteria orientate themselves towards the mucosa in close proximity to the epithelial cell layer where the $\mathrm{pH}$ is near neutral. The chemotaxis receptor TlpB is involved. Movement through the viscous mucosal layer is facilitated by a helical cell shape, which enables a screwlike movement. The cytosolic and membrane-associated bacterial enzyme urease buffers the environment by catalyzing the hydrolysis of urea, forming ammonia and carbon dioxide. Multiple bacterial adhesins mediate bacterial attachment to the epithelial cells, occasionally followed by invasion into the cells or traversing between intercellular junctions. Bacterial factors such as the adhesin SabA or the translocated effector protein CagA support the release of important nutrients to the apical side of the epithelial cells, either via the induction of inflammation or by the depolarization of the host cell. Persistent colonization is also enabled by a complex manipulation of the immune system. Specific modifications of LPS molecules enable molecular mimicry and structural alterations of the lipid A component which lead to low endotoxic activity. Additionally, H. pylori LPS can antagonize the pattern recognition receptor TLR4. The main flagella component FlaA also exhibits only weak TLR5-mediated immunogenic host cell responses, and the vacuolating toxin VacA can strongly interfere with immune cells by inhibiting T- and B-cell proliferation or phagosomal maturation of macrophages. VacA can also induce apoptosis of macrophages. The coating of the bacterial membrane with host cell molecules such as plasminogen and cholesterol protects $H$. pylori from recognition by the host, and the high genetic bacterial diversity allows fast adaption to changes in the environment. TLR, Toll-like receptor; LPS, lipopolysaccharide; iNOS, inducible nitric oxide synthase. 


\section{Manipulation of the Immune System}

H. pylori can persist for long time periods within the host without being extinguished by the immune system or by the frequent gastric environmental changes. Interactions of H. pylori with host epithelial surfaces are thought to elicit effective escape mechanisms, often causing cellular damage and inflammation. For example, intimate adherence via SabA has been shown to enhance inflammatory responses, which are assumed to facilitate access to essential nutrients released from damaged host cells [56]. Although direct evidence is lacking that inflammation is beneficial for $H$. pylori, the hypothesis still remains intriguing given that infection always elicits inflammation, regardless of symptoms. In addition, the delivery of cytotoxin associated antigen A (CagA), a key virulence factor, into the host cell via the type four secretion system (T4SS), depolarizes the epithelial cell to exploit the apical cell surface for use as a replicative niche and to obtain nutrients which are normally delivered to the basolateral side [57].

In general terms, immunity does not seem to exert a decisive influence on the establishment of an infection, as immune-compromised patients do not exhibit higher colonization rates [58]. Besides, adherence and the concomitant delivery of toxins, $H$. pylori possess a range of mechanisms to attenuate and manipulate the immune response, for example, the bacteria preferentially induce a T-helper cell 1 [Th1] type-based response, classified as typical cell mediated immunity, essential for the fight against intracellular pathogens [59]. H. pylori also expresses lipopolysaccharide (LPS) with a very low endotoxic and immunobiological activity compared to LPS of other Gram-negative bacteria [60] that can antagonize signaling mediated by the innate immune receptor, toll-like receptor 4 (TLR4) [61]. This antagonistic feature is based on specific modifications of the lipid A component [62] and strain-dependent expression of LPS O-antigens that are structurally related to Lewis blood group antigens found on human cells [63]. This molecular mimicry is not only involved in autoimmune responses but could also allow $H$. pylori LPS to evade recognition by the innate immune system [64]. The incorporation of cholesterol and its subsequent glycosylation in the $H$. pylori membrane [65] as well as the coating of the bacterium with host molecules such as plasminogen [66] might represent additional mechanisms of antigenic camouflage. Moreover, $H$. pylori flagella, structures which are normally recognized via the innate immune receptor TLR5, evoke only a very weak immune response due to a modified N-terminal TLR5 recognition site [67-69]. Other mechanisms by which $H$. pylori triggers the host immune system are based on bacterial factors that directly target host immune cells; for example, the vacuolating cytotoxin (VacA), which is encoded in the genome of all H.pylori strains, inhibits the nuclear translocation of the transcription factor nuclear factor of activated T-cells (NFAT), thereby blocking T-cell proliferation of $\mathrm{CD}^{+}$cells [70]. VacA also inhibits the proliferation of B-cells and $\mathrm{CD}^{+}$cells [71] and is able to disrupt the normal function of macrophages by either inducing apoptosis [72] or interrupting phagosomal maturation [73].
Bacterial arginase and $\gamma$-glutamyl transferase show similar functions in altering the normal function of T-cells [74, 75], while arginase and VacA additionally downregulate the expression of inducible nitric oxide synthase $[76,77]$.

\section{Genetic Diversity and Variation}

H. pylori exhibits a remarkable allelic diversity and genetic variability, typically involving endogenous (point) mutations and recombination, which result in every infected person carrying a distinct strain [78, 79]; however, differences between relatives are minimal [80]. Allelic diversity is promoted by a significantly higher mutation rate than found in many other bacteria [81], which may also explain the rapid development of high-level resistance to commonly used antibiotics such as clarithromycin. High mutation rates are most likely due to the lack of a complete DNA mismatch repair system (mutS1/MutL/mutH) and several enzymes involved in base excision repair $[82,83]$. A large repertoire of hyper-mutable genes frequently undergoes length changes as a consequence of slipped-strand mispairing-mediated mutagenesis, leading to numerous subpopulations within any large population [84]. Each of these subpopulations carry a specific combination of active and inactive phasevariable genes; for instance, LPS biosynthesis and outer membrane encoding genes, which allow $H$. pylori to rapidly adapt to environmental changes $[85,86]$. High natural competence for DNA uptake in combination with one of the highest intergenomic recombination rates found amongst pathogenic bacteria [87] also contributes to the high genomic variability between $H$. pylori isolates. Moreover, recent work has demonstrated that genetic exchange induced by damage of bacterial DNA contributes to persistence of H. pylori in its host [88]. Interestingly, a recent microarray analysis identified a large number of genes not previously associated with infection as essential for colonization of mice [89]. The majority of gene products were hypothetical, indicating that many other unknown bacterial factors may be required for colonization.

\section{Gastric Cancer and Ulcers: Mutually Exclusive Pathologies?}

10.1. Gastric Cancer. Although many H. pylori-associated diseases including peptic ulcer, gastric cancer, and MALT lymphoma only develop decades after infection (Figure 5), their medical burden is tremendous. Gastric cancer is one of the most common forms of cancer, with approximately 700,000 to 900,000 new cases diagnosed every year, and the second leading cause of cancer-related deaths worldwide [90]. Survival rates are very low, ranging from $15 \%$ if diagnosed during later stages of the disease to $65 \%$ if diagnosed early. Incidence rates vary widely geographically, and, in general, more males than females are affected $[50 \%$ lower incidence]. Although high-risk areas in Japan, China, Eastern Europe, and certain Latin America countries still remain [91], incidence rates worldwide have been declining for several decades [92]. 
Gastric adenocarcinomas are mainly divided into two histologically distinct forms, diffuse-type gastric adenocarcinoma, and intestinal-type adenocarcinoma (Lauren classification) each exhibiting different epidemiological and pathophysiological features [93]. Diffuse-type gastric adenocarcinoma is found predominantly in younger people, with no gender bias. It consists of individually infiltrating neoplastic cells that do not form glandular structures and are not associated with intestinal metaplasia [94]. The more prevalent form of gastric adenocarcinoma is called intestinal-type adenocarcinoma, which usually occurs in elderly people, predominates in men, and progresses through a well-defined chain of histological events, typically starting with a transition from normal mucosa to chronic gastritis, followed by atrophic gastritis and intestinal metaplasia which finally ends in dysplasia and adenocarcinoma [95]. $H$. pylori significantly increases the risk of developing both cancer types. We focus here mainly on the association between $H$. pylori and intestinal-type adenocarcinoma as the mechanisms of disease progression are better characterized as compared to diffuse-type gastric adenocarcinoma. Gastric cancers are also classified by their localization within the stomach: the most important distinction being between cardia (the proximal part of the stomach) and noncardia. H. pylori is the strongest risk factor for the development of non-cardia (distal) gastric cancer.

10.2. Peptic Ulcer Disease. Due to the high morbidity and mortality rates associated with peptic ulcer disease, which comprises both gastric and duodenal ulcers, this disease is regarded as a major medical threat. In most Western countries, morbidity from duodenal ulcer is more common than from gastric ulcer, even though the mortality rate is higher for gastric ulcer. In Japan, morbidity and mortality rates are generally higher for gastric ulcer than for duodenal ulcer [97]. Both ulcer types are defined as mucosal defects with a diameter of at least $0.5 \mathrm{~cm}$ penetrating through the muscularis mucosa. Whereas gastric ulcers mainly occur along the lesser curvature of the stomach, at the transition from corpus to antrum [98], duodenal ulcers can be normally detected in the duodenal bulb, or even with the pylorus. As with gastric cancer, recent epidemiological studies show a sharp decline in the incidence of ulcer disease [91], a direct consequence of the disease association with $H$.pylori and the now-possible effective antibiotic medication. Although the identification of $H$. pylori and its association with ulcer development completely changed the prevailing concept of "no acid, no ulcer", nonsteroidal anti-inflammatory drugs (NSAIDs) and low-dose aspirin are also an increasingly important cause of ulcers, even in H. pylori-negative patients [99].

\section{What Makes the Difference between Cancer and Ulcer?}

Although both gastric cancer and peptic ulcer disease are associated with $H$. pylori infection, mechanistically they appear to have entirely different origins and outcomes

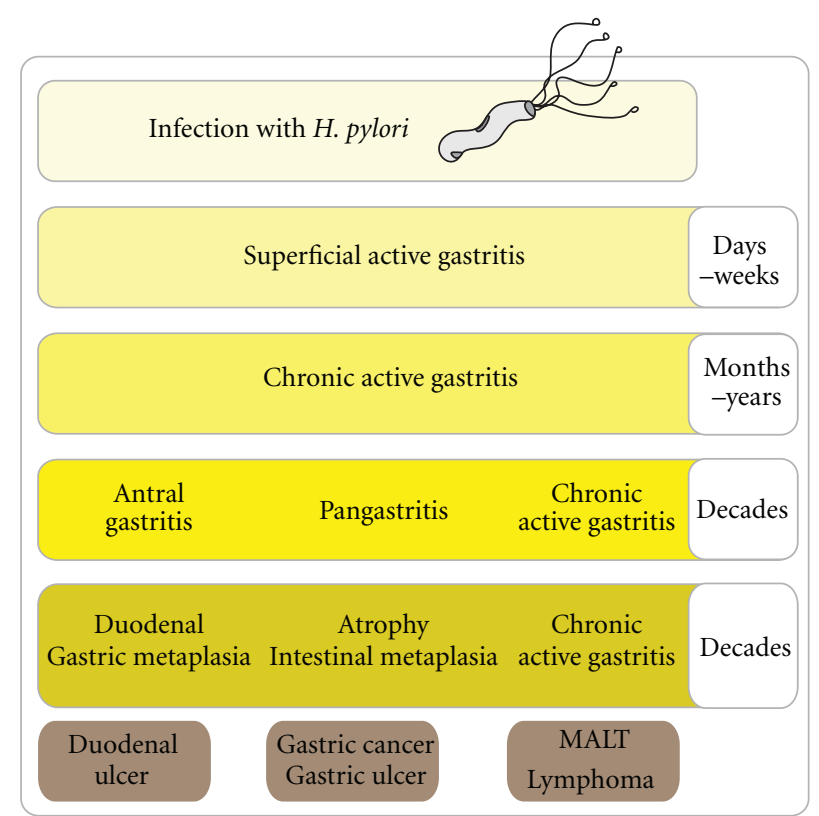

Figure 5: Time line of disease progression in $H$. pylori-infected persons. All infected individuals develop a superficial gastritis within the first weeks of infection, followed by a chronic active gastritis which develops after months or years. After decades, patients can develop antral gastritis or pangastritis, depending on the localization of the infection. The antral inflammation can lead to gastric metaplasia, which supports the growth of duodenal ulcer. The latter can lead to atrophy and intestinal metaplasia, two prerequisites for the development of gastric cancer or gastric ulcer. In contrast, constant chronic active gastritis can lead to the growth of MALT lymphomas. Adapted from Telford et al. [96].

(Figure 6). Gastric adenocarcinomas are malignant tumors which arise from uncontrolled proliferation of the epithelial cell layer and are accompanied by hypochlorhydria (low-acid secretion). The tumors mainly occur in the gastric antrum, body, or, to a lesser extent, in the fundus and originate from the inflammation of the entire stomach (pangastritis). By contrast, a peptic ulcer is a sore on the lining of the stomach (gastric ulcer) or duodenum (duodenal ulcer; DU) and originates from a disruption of normal wound-healing processes of the epithelial layer. Whereas acid secretion in duodenal ulcer is increased (hyperchlorhydria), gastric ulcers develop in low acid concentrations, as also observed with gastric cancer. This discrepancy is also due to the differences in the origin of prior inflammation, that is, predominantly in the antrum in cases of duodenal ulcer, but involving the entire stomach in cases of gastric ulcer [5]. While gastric cancer and duodenal ulcer can be easily discriminated from one other, gastric ulcer more closely resembles gastric cancer in localization and outcome. This relationship is also reflected in the observation that gastric cancer often occurs in patients with a history of gastric ulcers but hardly ever in patients with recent duodenal ulcers [100]. Moreover, gastric ulcer and gastric cancer patients are characterized by reduced acid secretion, corpus-predominant pangastritis, and an accelerated progression towards atrophic gastritis and intestinal metaplasia. The differences in gastric cancer and 


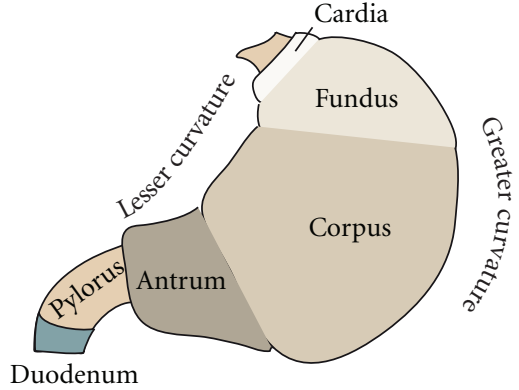

(a)

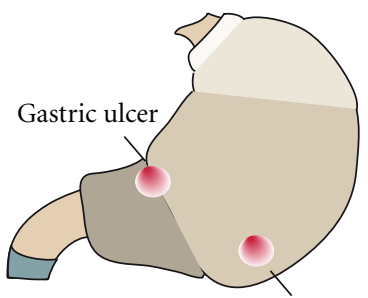

Noncardia gastric cancer

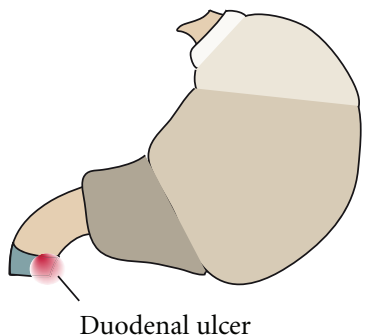

(b)

\begin{tabular}{|c|c|c|c|c|c|}
\hline Disease & Outcome & Proliferation & Inflammation & Acid secretion & \\
\hline $\begin{array}{l}\text { Gastric cancer } \\
\text { Gastric ulcer }\end{array}$ & $\begin{array}{l}\text { Tumor } \\
\text { Wound }\end{array}$ & $\begin{array}{l}\uparrow \\
\downarrow\end{array}$ & $\begin{array}{l}\text { Corpus-predominant } \\
\text { multifocal atrophic }\end{array}$ & Hypochlorhydria $\downarrow$ & $\begin{array}{l}\text { High risk of } \\
\text { gastric carcinoma }\end{array}$ \\
\hline Duodenal ulcer & Wound & $\downarrow$ & $\begin{array}{l}\text { Antral-predominant } \\
\text { diffuse gastritis }\end{array}$ & Hyperchlorhydria $\uparrow$ & $\begin{array}{l}\text { Little or no risk of } \\
\text { gastric carcinoma }\end{array}$ \\
\hline
\end{tabular}

(c)

Figure 6: Characteristics of H. pylori-mediated human disease. (a) Anatomical structure of the human stomach. (b) Localization of peptic ulcer (gastric and duodenal ulcer) and noncardia gastric cancer in the human stomach. (c) Differences in outcome, proliferation, inflammation, acid secretion, and risks for the development of gastric carcinoma.

duodenal ulcer are also mirrored in their worldwide prevalence, but not cooccurrence (Figure 7). Duodenal ulcer incidence is mainly concentrated in South Asia (e.g., India) and West Africa, whereas gastric cancer is mainly prevalent in Middle Asia and Middle Africa. Interestingly, some African (and Indian) populations have a high prevalence of $H$. pylori but low incidence of $H$. pylori- associated diseases, termed the "African enigma" [101]. One possible hypothesis posited for this anticorrelation is that enteric helminth infection in developing countries can attenuate $H$.pylori-induced atrophy and premalignant lesion by modulating the Th1driven immune response to bacterial infection $[102,103]$.

\section{H. pylori Virulence Determinants}

12.1. Strain Variations Trigger the Pathogenic Outcome of H.pylori Infections. The phenomenon that most $H$. pylori-infected patients develop no complications other than chronic active gastritis led to the notion that some strains may be more virulent than others. In fact, early investigations indicated that the severity of pathogenic outcome was correlated with the strain's ability to induce strong morphological changes, vacuolization and degeneration of in vitro cultured cells [104]. Because H. pylori can colonize the entire gastric epithelium, clinical outcomes are mainly dependent on the pattern of chronic inflammation induced. Therefore, bacterial factors involved in $H$. pylori-induced inflammatory responses constitute risk factors for both gastric cancer and peptic ulcer. Despite the wide genetic diversity of $H$. pylori hampering the search for bacterial factors involved in pathogenesis, several genomic loci encoding virulence factors, such as the cag pathogenicity island (cagPAI), the toxin VacA, and the Bab2 adhesin, have been strongly associated with an increased risk of developing gastric cancer and peptic ulcer disease $[105,106]$. Like disease prevalence, the distribution of these genomic loci varies geographically. While the VacA-encoding gene can be found in all strains, albeit with various allelic combinations, only $60-70 \%$ of all Western strains carry cagPAI. In contrast, cagPAI is present in $95-100 \%$ of all Asian strains. The bab2 gene is present in around $85 \%$ of all strains.

12.2. The cag Island and the Virulence Factor CagA. One of the most important strain-specific determinants influencing H. pylori-mediated pathogenesis is cagPAI. This horizontally acquired genomic locus of approximately $40 \mathrm{~kb}$ contains 31 genes $[83,107]$ that encode a T4SS. It was first detected while searching for the genomic localization of the bacterial protein CagA, a marker for $\mathrm{H}$. pylori-associated diseases [108]. The cagA gene, located at the $3^{\prime}$ end of cagPAI, encodes the only known bacterial effector protein translocated by the T4SS into host cells. The T4SS forms a membrane protrusion, often inaccurately referred to as a needle-like structure $[109,110]$ : it is not comparable to the static form of a bacterial type 3 secretion system [T3SS], which truly resembles an injection syringe [111]. CagA is often detected on the surface of the T4SS; it becomes translocated into epithelial cells and to a lesser extent into hematopoietic cells 


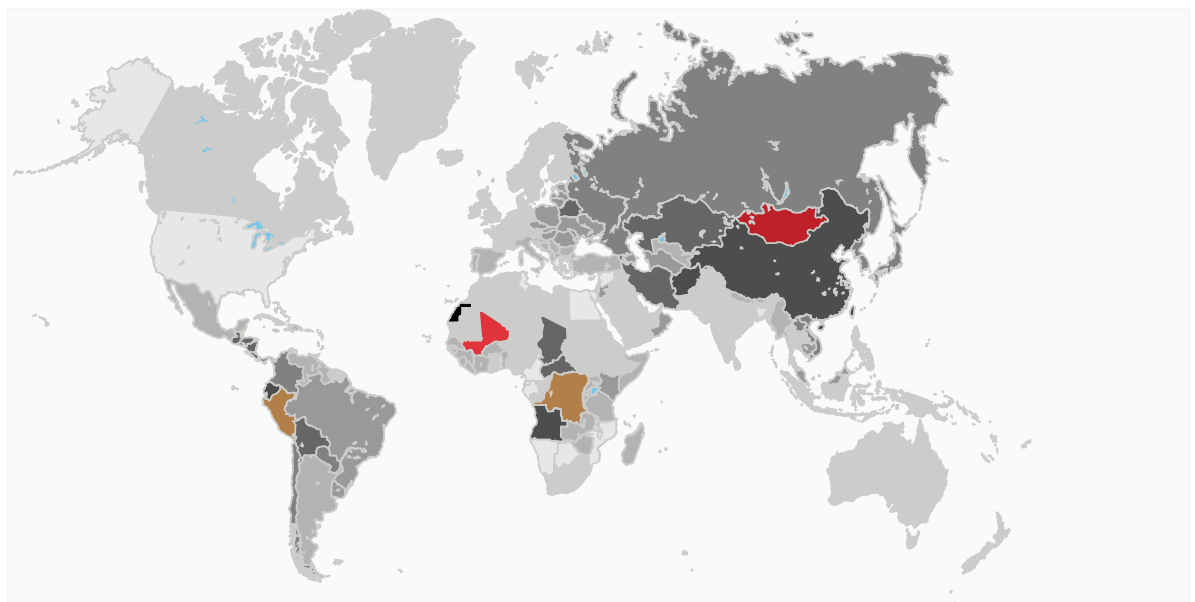

Death rates from gastric cancer by country per 100000 inhabitants

\begin{tabular}{|c|c|}
\hline$\square<3.5$ & ㅁ 21.5-26 \\
\hline $3.5-8$ & ( 26-30.5 \\
\hline $8-12.5$ & ㅁ 30.5-35 \\
\hline 12.5-17 & - 35-40 \\
\hline 미 $17-21.5$ & ㅁ $40-50$ \\
\hline
\end{tabular}

(a)

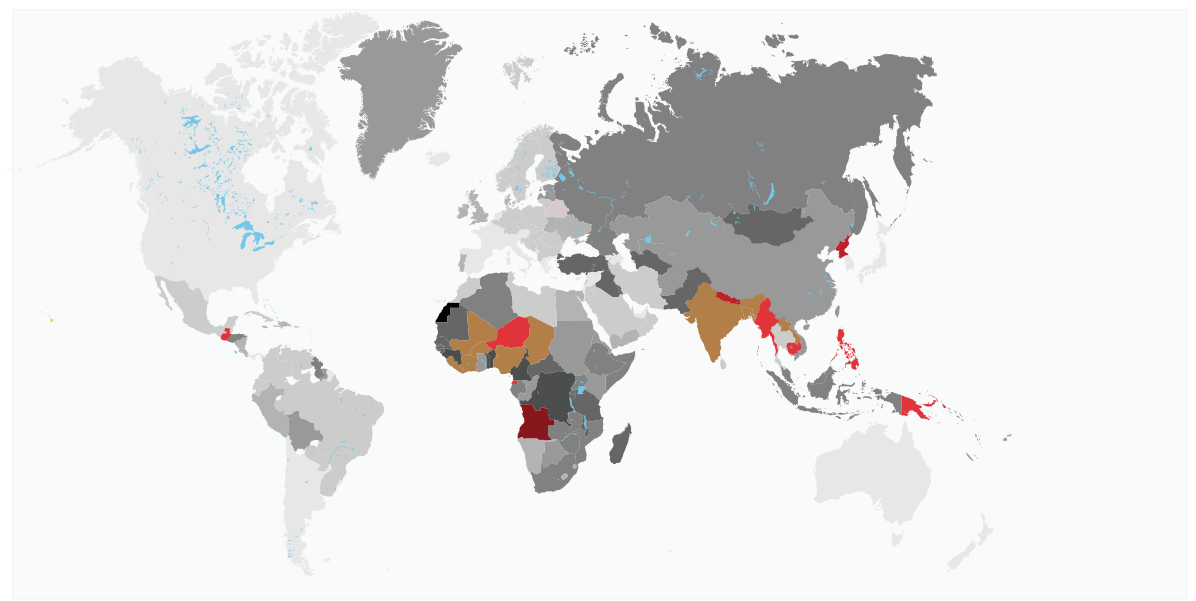

Disability/-adjusted live year (DAILY) rates from peptic ulcer disease by country per 100000 inhabitants

$\square<20$
$20-40$
$\square 0-60$
$\square 0-80$
$\square$
$\square 0-120$
$\square$
$120-140$

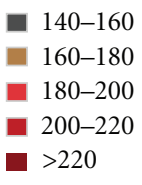

(b)

FIGURE 7: Worldwide gastric cancer death rates and peptic ulcer disability rates. H. pylori infection prevalence mirrors the outcome of H. pylori-associated disease. The highest gastric cancer death rates are concentrated in Middle Asia and Middle Africa, whereas the peptic ulcer causes disabilities mainly in West Africa and South Asia. Data derived from Death and DALY estimates for 2004 by cause for WHO Member States (Persons, all ages) (2009-11-12).

$[112,113]$. Intriguingly, CagA has also been detected on the surface of outer membrane vesicles (OMVs) secreted by H. pylori [114]. The interdependence of T4SS function, OMV formation, and CagA translocation likely remains an interesting area of future investigation.
Surface-exposed integrin molecules act as host cell receptors which permit the successful delivery of CagA and, thus, play a key role in T4SS functionality. In this context, CagL, a T4SS component, was proposed to have an important function by mediating binding between $\beta 1 \alpha 5$ integrins and 
its RGD-domain [115]. Although contradictory data have been published [116], recent observations could support the CagL-integrin interaction concept by showing that CagL activates the integrin-binding molecule ADAM17 via mediating its dissociation from $\beta$-1integrin [117]. Accordingly, ADAM17 inhibits the expression of the gastric $\mathrm{H}^{+}, \mathrm{K}^{+}$ATPase $\alpha$ subunit via the transcription factor nuclear factor $\kappa \mathrm{B}(\mathrm{NF}-\kappa \mathrm{B})$. Since the $\mathrm{H}^{+}, \mathrm{K}^{+}$-ATPase $\alpha$ subunit is involved in acid secretion, these data demonstrate a T4SS-dependent molecular mechanism for hypochlorhydria and indicate that the influence of cagPAI on the development of gastric cancer and gastric ulcer is more pronounced than on the induction of duodenal ulcer (Figure 8). Additional cagencoded proteins ( $\mathrm{CagA}, \mathrm{CagI}$ and $\mathrm{CagY}$ ) have been shown to bind $\beta 1$-integrin in order to induce conformational changes of integrin heterodimers which enable CagA translocation [116]. Since integrins are not located at the apical membrane but are expressed at the basolateral side, $H$. pylori would have to reach the basolateral surface to efficiently activate the T4SS. Moreover, in addition to the normal expected apical niche, viable bacteria have been observed within paracellular spaces and the gastric lamina propria [47]. Accordingly, H. pylori induces the shedding of E-cadherin to disrupt adherence junction complexes in a CagA-independent manner [118], enabling bacteria to enter the basolateral side of formerly closed epithelial cell layers (Figure 8).

The status of CagA as a marker of pathogenic disease resulted from the observation that patients with elevated antibody titers against CagA showed higher incidences of both peptic ulcers [119] and gastric adenocarcinoma [120, 121]. The association of CagA with gastric cancer was cemented by subsequent work showing that the expression of CagA in transgenic mice leads to gastric epithelial cell proliferation and the development of gastric adenocarcinoma [122]. Data showing CagA-dependent attenuation of apoptosis in Mongolian gerbils [123] and that CagA-induced blockage of endocytosis mediated the downregulation of the proliferation controlling epidermal growth factor receptor (EGFR) [124] further support the hypothesis that CagA has oncogenic features. CagA can also provoke proinflammatory responses [125] and activate the signal transducer and activator of transcription 3 (STAT3) pathway, thought to play a role in gastric cancerogenesis (Figure 8) [126]. Nevertheless, strains lacking cagPAI, which consequently do not express CagA, have also been found in patients with peptic ulcers or gastric cancer, albeit at lower frequencies. The mechanisms by which CagA mediates gastric human disease are still not fully understood. Future work is required to unravel the complex but extremely efficient manipulation of important host cell signaling cascades facilitated by this multifunctional protein.

Recent investigations have shown that surface-exposed CagA interacts with externalized phosphatidylserine to initiate its entry into host cells [127]. Following its injection into epithelial cells, CagA undergoes tyrosine phosphorylation $[128,129]$, mediated by the nonreceptor tyrosine kinases Src [130] and Abl [131], two well-known oncoproteins (Figure 8). Phosphorylation is tightly controlled by $H$. pylori in a time-dependent manner; Src is only activated during initial stages of infection $(0.5-2 \mathrm{~h})$ [132], whereas $\mathrm{Abl}$ is strongly activated at late infection time points $(2-8 \mathrm{~h})$ [133]. Phosphorylation takes place at specific C-terminal Glu-ProIle-Tyr-Ala (EPIYA) sequence motifs of CagA which can vary in number in a strain-dependent manner [134, 135]. Four EPIYA-sites-A, B, C, D-have been identified. The EPIYA-A and EPIYA-B motifs are distributed worldwide, whereas the EPIYA-C motif is more prominent in strains from Western countries (e.g., Europe, Australia, North America) and some Asian countries (Malaysia and India). EPIYA-D sequence motifs are mainly present in East Asian CagA (Japan, China, and Korea) and are linked to the development of gastric cancer [136].

It is not only the sequence motif but also the number and variation of phosphorylation sites that determine the pathogenic potential of CagA. Elevated phosphorylation, caused by an increase in number of EPIYA sites, leads to enhanced binding of another oncoprotein, the tyrosine phosphatase SHP-2. After binding to CagA, SHP-2 is functionally deregulated [137]. CagA recruits and activates SHP-2 in a phosphorylation-dependent manner and induces a Rasindependent response which leads to dramatic morphological changes of the host cell, reflected by a strong actin polymerization and cellular elongation (Figure 9), termed the "hummingbird" phenotype [138]. Expression of EPIYA$A$ and EPIYA-B sites correlate with the ability of CagA to bind the tyrosine kinase Csk, which in turn inhibits Src-dependent CagA-phosphorylation, thereby, attenuating the induction of cellular elongation by the CagA-SHP-2 complex [139]. These contradictory functions of different EPIYA sites highlight the complex and multifunctional role of CagA in H.pylori-mediated disease. That CagA interacts with a surprisingly high number of host cell signaling factors further complicates the elucidation of CagA function. Interactions can be phosphorylation dependent or independent, and interaction partners range from kinases to adaptor molecules [140]. In addition to CagA-independent interactions reported by Weydig and colleagues [118], a phosphorylation-independent interaction between Zonula occludens-1 (ZO-1), a junctional adhesion molecule, and CagA was shown to contribute to an alternative mechanism of epithelial layer disruption [141]. The CagA-ZO-1 association was closely linked to an ectopic assembly of tight junction components at the site of bacterial attachment which altered the composition and function of the apical junctional complex (see Figure 8).

Binding between CagA and the PAR1/MARK kinase complex, which has an essential role in the maintenance of epithelial cell polarity (Figure 8 ), has also been shown to be phosphorylation independent [142]. Association with CagA inhibits PAR1 kinase activity leading to the dissociation of PAR1 from the membrane causing junctional and polarity defects. These effects are dependent on conserved amino acid motifs at the C-terminus of CagA, termed the CagA multimerization (CM) domain [143]. The binding of PAR1 by the CM domain mediates the dimerization of CagA, thereby, strengthening the bond between CagA and SHP-2. The functional relevance of this association has been further corroborated by cocrystallography analysis of CagA, showing 


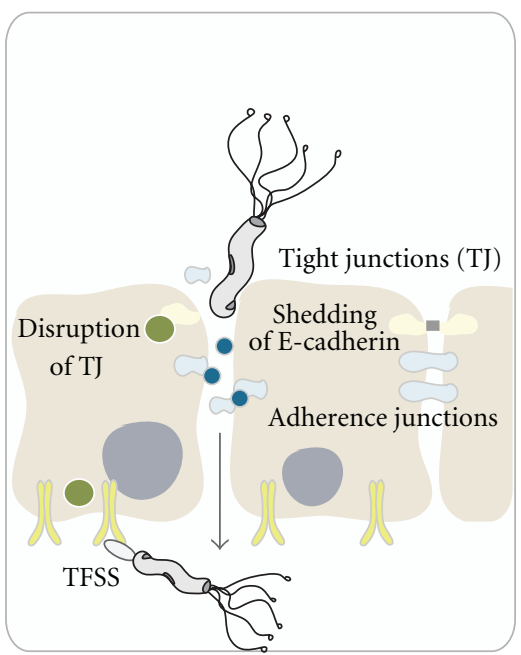

Integrin

E-cadherin

ZO-1

- CagA

- Protease

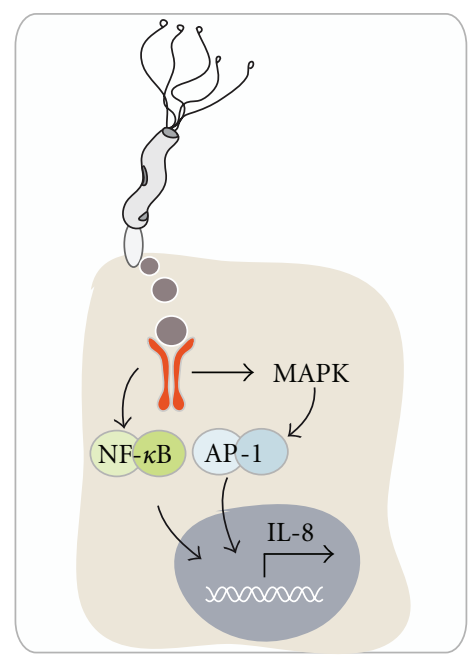

Peptidoglycan

NOD-1

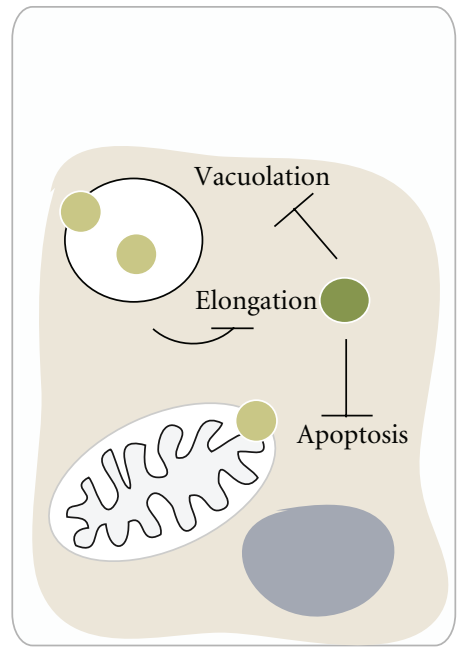

VacA

CagA (a)

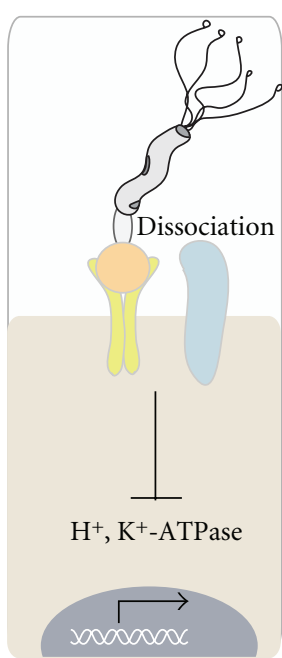

CagL
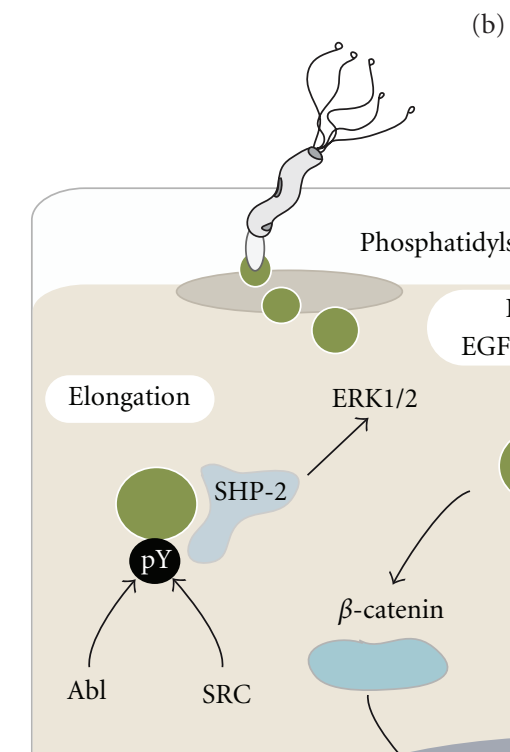

(b) (c)

ADAM17

Abl

SRC

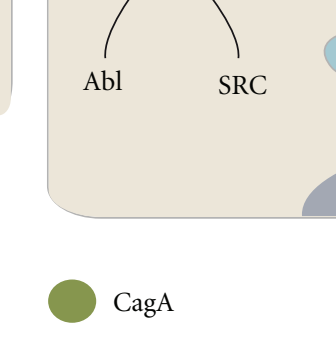

CagA (e)

FIGURE 8: Molecular pathogenesis. H. pylori has evolved different mechanisms to destroy intercellular junctions. (a) The secretion of a bacterial protease leads to the shedding of E-cadherin, an important component of adherence junctions. The toxin CagA, which is translocated in the epithelial cell by the bacterial T4SS, interacts with ZO-1, thereby, destroying the formation of tight junctions. By crossing the intercellular space, $H$. pylori reaches basolateral integrins which function as T4SS receptors. (b) The T4SS also delivers peptidoglycan into the host cell. Peptidoglycan is recognized by NOD-1 which activates the transcription of proinflammatory genes such as IL8 via the transcription factors NF- $\kappa$ B and AP-1. AP- 1 is activated via MAP kinases (MAPK). (c) VacA induces vacuolization as well as mitochondria-mediated apoptosis in epithelial cells, whereas CagA induces drastic morphological changes such as cellular elongation. CagA and VacA counteract each other. (d) The T4SS component CagL mediates the interaction between the T4SS and integrins, thereby leading to the dissociation of the metalloproteinase ADAM17, a process which inhibits the expression of the $\mathrm{H}^{+}, \mathrm{K}^{+}$-ATPase. (e) CagA is translocated via phosphatidylserine-rich domains into the host cell where it is phosphorylated via Src kinases and Abl. Phosphorylation leads to an interaction with the tyrosine phosphatase SHP-2 which induces a constant activation of ERK1/2. These events cause cellular elongation. Furthermore, CagA can inhibit EGFR endocytosis thereby blocking receptor degradation. CagA also activates $\beta$-catenin and STAT3 which leads to transcription of oncogenes. $\beta$-catenin activation can also be CagA independent, induced by an AKT-mediated phosphorylation of the $\beta$-catenin inhibitor GSK3 $\beta$. Interaction between CagA and the PAR1/MARK complex can lead to a depolarization of the host cell. 

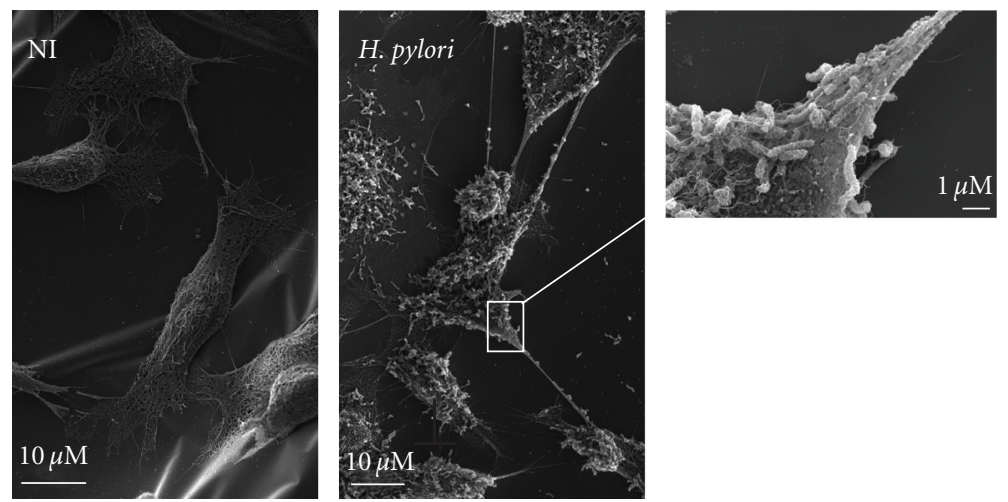

FIgURE 9: $H$. pylori-infected human gastric epithelial cells. Scanning electron microscopy pictures from cytoskeletal preparations of noninfected (NI) and infected (H. pylori) human gastric epithelial adenocarcinoma cells (AGS). Infected cells show dramatic morphological changes of the cytoskeletal network.

that the C-terminal CM domain blocks PAR1 function by occupying the substrate-binding site of PAR1 [144]. Thus, the CagA-PAR1 association not only causes polarity defects but also promotes the morphogenic response induced via the interaction of CagA and SHP-2.

Another host cell factor potentially influencing cancerogenic responses in conjunction with CagA is the ubiquitously expressed protein $\beta$-catenin (Figure 8 ). While membrane bound $\beta$-catenin is an important component of adherence junctions, cytoplasmic $\beta$-catenin is a downstream signaling molecule of the WNT signal transduction pathway. Upon dissociation of the inhibitory $\beta$-catenin-interaction partner $\operatorname{GSK} 3 \beta, \beta$-catenin is translocated into the nucleus where it induces the transcription of target genes involved in cancerogenesis [145]. After translocation, CagA induces nuclear accumulation and functional activation of $\beta$-catenin via the disruption of the membrane-bound E-cadherin/ $\beta$-catenin complex [146-148]. H. pylori infection was also shown to lead to AKT dependent, but CagA-independent, $\beta$-catenin activation through phosphorylation (Figure 8 ) and subsequent inactivation of the $\beta$-catenin inhibitor GSK3 $\beta$ [149].

Studies of CagA-host cell interactions have provided many fundamental insights into the molecular mechanisms by which $H$. pylori induces potentially cancerogenic host cell responses; however, the mechanisms underlying the association of CagA with ulceration remain elusive. It has neither been postulated nor shown that CagA could promote a delay in wound healing or an inhibition of cell proliferation. By contrast, VacA could inhibit proliferation, whereas undialyzed $H$. pylori blocked both wound healing and cell proliferation, indicating the existence of CagA- and VacAindependent mechanisms leading to the promotion of ulcer development [150]. Future work is undoubtedly required to solve the remaining conundrums.

12.3. The cag Island and the Delivery of Peptidoglycan. Besides CagA translocation, the T4SS is also involved in the production of chemokines, such as interleukin-8 (IL-8). This process is mediated by the combinatorial activation of the host cell transcription factors NF- $\kappa \mathrm{B}$ [151] and AP1 , the latter activated by the MAPK pathway $[152,153]$.
MAPK phosphorylation and activation of AP-1 are dependent on the intracellular pattern recognition factor NOD-1 (nucleotide-binding oligomerization domaincontaining protein 1) [154], which is known to recognize universal bacterial components such as peptidoglycan. Indeed, peptidoglycan was suggested to be translocated into the host cell in a T4SS-dependent manner [155], thereby, inducing the activation of NF- $\kappa \mathrm{B}$ via NOD-1 (Figure 8). Delivery is mediated via cholesterol-rich microdomains (lipid rafts) of the host cell plasma membrane [156]. Delivery of peptidoglycan, however, can also occur independently of the TFSS, instead mediated by bacterial OMVs which enter human gastric epithelial cells via lipid rafts [157]. This mechanism provides an explanation for the varying dependency of IL-8 secretion in different epithelial cell lines on the T4SS [113]. The cell-line specificity of TFSS-independent IL-8 secretion could be due to variations in the composition of lipid raft associated receptors, enabling TFSS-dependent peptidoglycan delivery and/or OMV-mediated peptidoglycan translocation.

Both CagA and peptidoglycan seem to be responsible for the induction of a T4SS-dependent proinflammatory response, although the ability of CagA to mediate IL-8 expression is not identical for all CagA-expressing strains $[125,158]$. Observations that CagA and NOD-1 accumulate in a novel type of intracellular host cell structure enforce the model that CagA and peptidoglycan can induce immuneinflammatory and proliferative responses in the gastric epithelium with potential pathologic relevance [159]. Recent work, however, shows that the deletion of the bacterial deacetylase HP0310, which is required for normal synthesis of peptidoglycan, results in an increased delivery of CagA into host cells [160], indicating that even in the absence of peptidoglycan $H$. pylori retains the ability to initiate a proinflammatory response.

12.4. Vacuolating Toxin VacA. H. pylori VacA is a paradigmatic type-V-secreted bacterial toxin that contributes to the establishment of successful infection and virulence in multiple ways. Similar to CagA, it has been shown to be responsible for epithelial ulceration [161]. VacA was initially identified 
through its ability to cause vacuolation in cultured epithelial cells [104]. VacA-induced vacuoles are positive for marker proteins of the late endocytic compartment, including Rab7 [162, 163], LAMP1, and Lgp110 [164]. It is supposed that VacA induces the formation of large vacuoles after its internalization into endosomal structures, where it forms anion-selective channels, subsequently leading to swelling of VacA-containing endosomal compartments [165]. Although vacuolation is readily observed in vitro, it does not seem to occur in vivo [5].

The VacA amino acid sequence shares no similarities with other prokaryotic or eukaryotic proteins, and although all strains contain $v a c A$, their sequences vary remarkably. $v a c A$ alleles are distinguished by differences in the $5^{\prime}$ region (s-region) and midregion (m-region). Strains possessing s1m1 type alleles are associated with an increased risk of peptic ulceration and gastric carcinoma as compared to strains harboring other allelic forms, for example, s $2 \mathrm{~m} 2$ $[166,167]$. In countries with high rates of distal cancer, such as Colombia and Japan, most H. pylori strains contain the more pathogenic vacA allele types [168]. In vivo experimental studies have corroborated the association, reporting mucosal injury and gastric inflammation after the administration of large quantities of VacA into the stomachs of mice [169] and demonstrating, using isogenic wild-type and vacA-null mutant strains that VacA contributes to severe gastritis in gerbils [170].

Monomeric $88 \mathrm{kDa}$ VacA molecules are secreted into the extracellular space [171] via type V secretion [172] where they self-assemble into water-soluble oligomeric structures to form anion-selective membrane channels. However, VacA can also remain associated with the bacterial membrane as a biologically active molecule and can be taken up by the host cell in a contact-dependent mechanism [173]. The mature form can undergo specific proteolytic cleavage to yield the functionally different subunits, p33 and p55 [174]. The p33 domain contains a hydrophobic sequence that is involved in pore formation $[175,176]$ and vacuolating cytotoxin activity [177], whereas the p55 fragment contains cellbinding domains [178]. VacA can bind multiple epithelial cell surface molecules, including the transmembrane protein receptor-type tyrosine protein phosphatase- $\zeta$ (PTPRZ1) [179], fibronectin [180], EGFR [181], CD18 on T-cells [182] as well as various lipids [183] and sphingomyelin [184].

Besides its ability to induce the vacuolation of epithelial cells in vitro, VacA can also stimulate apoptosis (Figure 8), a process restricted to the more pathogenic allelic combination s1m1 [185]. The $\mathrm{p} 34$ VacA subunit modulates mitochondrial membrane permeability [186] by a mechanism dependent on toxin channel activity, ultimately resulting in cytochrome $c$ release and the subsequent activation of caspase 3 [187]. Since VacA mutants that are defective in forming membrane channels fail to elicit cytochrome $c$ release, it seems likely that VacA-mediated alterations of mitochondria are based on the formation of VacA channels in the mitochondrial membrane [188]. In stark contrast to VacA, CagA exhibits antiapoptotic features [123], leading to the hypothesis that these two key virulence factors may have antagonistic functions. Indeed, CagA has been shown to inhibit VacA-induced apoptosis [189] and reduce vacuolation of epithelial cells, while VacA can inhibit CagA-mediated cellular elongation [190]. Within the latter scenario, active VacA exerts its inhibitory impact by interfering with signaling pathways known to be crucial for cell scattering and elongation, for example, the EGFR pathway [191]. The opposing behavior of these two key virulence factors is even more fascinating because cagPAI-positive strains are most likely to possess the more toxic s1 forms of VacA, whereas cagPAI-negative strains generally harbor nontoxic s2 forms. This is not due to genetic linkage as the gene loci are not close to each other. The antagonistic properties of VacA and CagA could represent a strategy to protect the ecological niche of $H$. pylori against its own bacterial virulence factors, which are initially needed for colonization but later have detrimental consequences for the human host. Moreover, the immunosuppressive properties of VacA may play an important role in enabling $H$. pylori to persistently colonize the human host.

12.5. Additional Virulence Attributes. Besides cagPAI, CagA, and VacA, other bacterial virulence effectors are known to trigger $H$. pylori-mediated gastric disease. The duodenal ulcer-promoting gene A $(d u p A)$, encoding a VirB4 ATPase homolog, is associated with an increased risk of developing duodenal ulcer but a reduced risk of gastric atrophy and gastric cancer [192]. Recent work indicates this could be due to dupA-mediated induction of proinflammatory cytokine secretion by mononuclear cells [193].

Another gene implicated in peptic ulcer disease is iceA1, albeit with considerable geographic differences in expression [194]. The gene encodes a CATG-recognizing restriction endonuclease with significant sequence homology to nlaIIIR, an endonuclease of Neisseria lactamica [195, 196], and is induced by bacterial adherence to the gastric epithelium [197].

The Hop protein family member, bacterial outer membrane protein OipA $(\mathrm{HopH})$ has also been identified as a potential disease-promoting factor. Like vacA, the oipA gene is present in all $H$. pylori strains, but its expression is modified by phase variation, caused by variable numbers of CT dinucleotide repeats in the $5^{\prime}$ region. OipA was originally identified as a proinflammatory response-inducing protein, but may also serve as an adhesin [25]. Its expression correlates with increased in vitro and in vivo production of IL-8 [198] and, more recently, OipA has been shown to be involved in the activation of the focal adhesion kinase (FAK) and cytoskeletal reorganization, resulting in an altered morphological host cell phenotype [199]. Other adhesins of the Hop protein family such as SabA (HopP) and BabA (HopS) are also categorized as bacterial virulence factors since they mediate bacterial adherence to the host and thus influence pathogenesis.

12.6. Host Cell Determinants of H. pylori Pathogenesis. It has become apparent that not only the pathogen but also host 
genetics play an important role in determining the clinical manifestation of $H$. pylori infections. Indeed, host genetic polymorphisms affecting expression levels of important genes involved in pathogenicity have been demonstrated to influence susceptibility and severity of $H$. pylori infection. In general, genetic polymorphisms in proinflammatory genes tend to increase the risk of gastric cancer, as demonstrated for IL-1, a potent proinflammatory cytokine and the most prominent inhibitor of gastric acid secretion [200]. IL-1 is encoded by a gene cluster containing the polymorphic IL-1B (IL-1 cytokine-encoding gene) and IL-RN (IL-1 receptor antagonist encoding gene) encoding genes. Several polymorphisms, such as IL-1B $*-31 \mathrm{C}$, lead to the expression of large quantities of IL- $1 \beta$ and a subsequent reduction in acid secretion [201]. Reduced acid secretion is linked to corpus-predominant colonization by $H$. pylori, which results in pangastritis formation of atrophic gastritis and thus an increased risk of gastric cancer and gastric ulcer disease [202207]. Similar effects have been described for polymorphisms in other inflammation-associated genes, for example, the genes encoding tumor necrosis factor alpha (TNF- $\alpha$ ) and IL-10. Distinct TNF- $\alpha$ polymorphisms lead to increased TNF- $\alpha$ expression, which influences, in concert with IL-1, gastrin production and thus acid production by parietal cells [208]. In addition to alterations in acid production, cancer patients carrying the IL1B-511T/T genotype show significantly higher methylation levels of specific genes than patients with other genotypes. This leads to the assumption that the L1B-511T/T allele is associated with enhanced hypermethylation of multiple CpG island loci, which might contribute to an increase in the risk of gastric cancer in $H$. pylori-infected individuals [209]. Similar to specific IL-1 genotypes, these TNF- $\alpha$ polymorphisms are, therefore, strongly linked to $H$. pylori infection and increased risk of gastric cancer $[202,210,211]$. In addition, specific IL-10 haplotypes lead to higher cytokine expression levels, thereby, shifting the balance towards an anti-inflammatory host cell $[202,212-214]$; this is associated with the colonization of more virulent $H$. pylori strains [215]. By contrast, specific IL-10 haplotypes actually induce lower IL-10 expression levels, favoring proinflammatory responses and an associated increased risk of gastric cancer. Polymorphisms in other gene types may also influence $H$. pylori-induced disease; for instance, a specific allelic variant of the TLR-9 promoter gene sequence creates a potential NF- $\kappa \mathrm{B}$ binding site that increases the transcriptional activity of the gene [216]. Since altered NF- $\kappa \mathrm{B}$ activation is associated with premalignant gastric changes, this genotype could also be involved in H. pylori-mediated gastric cancer. Moreover, genes encoding IL-8 and NOD1 have also been shown to be associated with $H$. pylori-induced duodenal ulcer and gastritis [217]. Interestingly, the number of polymorphisms seems to influence the clinical outcome dramatically. Whereas single polymorphisms of genes involved in proinflammatory responses may increase the risk of cancer development only two- to threefold, the presence of multiple genotypes increases the risk further $[205,218]$.

\section{Beyond Peptic Ulceration and Gastric Cancer}

13.1. MALT Lymphoma. All H. pylori-infected persons have a significantly increased risk for the development of gastric MALT lymphoma [7]. Accordingly, the majority of MALT lymphoma patients are $H$. pylori positive [219]. In very rare cases, a monoclonal population of B-cells arises from this mucosal tissue and proliferates to form a MALT lymphoma via chronic T-cell driven antigenic stimulation. The incidence of MALT lymphoma in $H$. pylori-infected patients is estimated to occur in less than $1 \%$ of $H$. pylori-positive subjects [220], but due to diagnostic controversies, based on difficult histological interpretations, and the rarity of this disorder, no exact figures are known. In contrast to gastric cancer, where the "point of no return" often abolishes successful treatment of adenocarcinoma via the eradication of $H$. pylori, the eradication of the bacteria in MALT patients can lead to complete remission in $60 \%-80 \%$ of patients with stage 1 low-grade gastric MALT lymphoma [221-224]. However, $10-35 \%$ of patients in complete remission after $H$. pylori eradication showed recurrent disease, necessitating the implementation of mandatory long-term followup examinations [225]. Recurrence in specific patients could be due to the presence of at $[11 ; 18]$ (q21; q21) translocation, which is associated with API2-MALT1 fusion. API2 is involved in apoptosis, and the latter resembles a caspase-like protein. The gene fusion leads to the suppression of apoptosis, and several studies have shown that MALTlymphoma patients with this translocation do not or only rarely respond to $H$. pylori eradication [226, 227]. Despite these caveats, $H$. pylori eradication has been designated as the first choice treatment in the Maastricht III Consensus Report [228].

13.2. GERD. The development of gastroesophageal reflux disease (GERD) has long been considered to be independent of $H$.pylori as it occurred at the same frequency in $H$. pylori-positive and -negative patients [229]. An intriguing, albeit controversial, role for $H$. pylori has emerged from observations that the bacterium's prevalence was low in GERD patients [230], and that the incidence of GERD increased after H. pylori eradication [231], suggesting that the bacteria play a protective role. Moreover, $H$. pylori-induced corpus gastritis has been shown to reduce acid secretion and thus prevent patients from contracting GERD [232]. Conflicting evidence exists, however, demonstrating that $H$. pylori eradication has no impact on either the new cases of GERD [233] or the worsening of preexisting cases when treatment has been withdrawn during disease remission. This inverse correlation between $H$. pylori and GERD, if it exists, warrants further study before sound scientific conclusions can be made.

13.3. Extra-Gastrointestinal Disease. A putative role for H. pylori in the development of idiopathic thrombocytic purpura (ITP) was first described by Gasbarrini and colleagues [234]. Subsequent studies showed that platelet counts 
in patients with ITP returned to normal levels after the eradication of $H$. pylori $[235,236]$. In addition, anti-CagA antibody titers have been shown to be significantly decreased in patients responsive to $H$. pylori eradication therapy in comparison to nonresponsive patients, implicating CagA in ITP pathogenesis [237].

A number of studies have also demonstrated a link between the pathogen and iron deficiency anaemia (IDA), another extragastrointestinal disease. The prevalence of $H$. pylori was highly increased in patients with unexplained IDA, and patients showed normal haemoglobin levels after $H$. pylori eradication therapies [238]. Interestingly, despite normal serum transferrin and iron levels, soluble transferring receptor (sTFR) was significantly elevated in $H$. pylori-infected children, suggesting that sTFR is a more reliable indicator of iron status than serum iron or ferritin.

Similar to GERD, a negative correlation between $H$. pylori and disorders such as asthma, allergy, and atopic disease has been postulated. In general, $H$. pylori prevalence and asthma as well as allergic diseases show an inverse association [239]; in children not predisposed to atopy, an inverse correlation between $H$. pylori and eczema has been observed [240]. Furthermore, due to the observations that diminished exposure to microbes during childhood leads to an increase of atopic disease [241], the debate regarding whether $H$. pylori should always be eradicated upon diagnosis has been heightened.

\section{Diagnosis and Treatment}

Diagnostic tests for $H$. pylori are generally divided into two categories: invasive and noninvasive. Invasive tests comprise the histological examination of gastric specimens. Noninvasive tests are based on peripheral samples such as blood, breath, stools, urine, and saliva, in order to detect antibodies, bacterial antigens, or urease activity. The choice of a specific test always depends on local experience and clinical settings, but usually a combination of two methods is often recommended since, for example, the detection of $H$. pylori-specific antibodies does not ultimately reflect a current infection.

Although H. pylori is sensitive to a wide range of antibiotics in vitro, they all fail when applied as monotherapy in vivo. Therefore, a combined therapeutic strategy is used, usually including two antibiotics (clarithromycin, combined with amoxicillin or metronidazole) and either a bismuth compound or a proton pump inhibitor (PPI). Rarely, quadruple therapies are used in which the bismuth compound and PPI are used in combination with two antibiotics. The use of these drugs has resulted in effective therapies, with eradication rates over $80 \%$. During the past several years, however, resistant bacteria have been detected constantly $[242,243]$, leading to the search for alternative drugs and treatment strategies.

In the past decade, much effort has been devoted to the development of vaccination strategies. Based on the successful elimination of Helicobacter felis after mucosal immunization of mice with urease [244], the focus of much research has been the induction of a humoral or Th2-driven immune response. To date, however, effective vaccination has only been observed in animal models and no human vaccine trial has been successful [245]. The failure to replicate the success of the vaccine in humans may be due to differences in $H$.pylori-specific immune responses or anatomical differences of the stomach. For instance, one of the main surface bacterial virulence factors, cagPAI, is usually switched off in mice.

Vaccines and antibiotics are not the only ways to prevent and cure $H$. pylori infection or $H$. pylori-associated disease. $H$. pylori-positive individuals infected with helminths have standard levels of $H$. pylori colonization rates and gastritis patterns, but they develop significantly less $H$. pylori-associated disease [246, 247]. These are intriguing observations that might result in low-dose administration of immunomodulating agents to $H$.pylori-positive patients, which have the same consequences as enteric helminth infections.

Another approach is the application of probiotics. There is convincing evidence that $H$. pylori is killed by Lactobacilli both in vitro and to a limited extent in vivo [248-250]. Furthermore, Lactobacilli show a positive impact on some H. pylori therapy-related side effects, and recent studies suggest that Lactobacilli supplements could be effective in increasing eradication rates [251].

\section{Closing Remarks}

The discovery that the world's most common bacterial infection is clearly associated with the development of severe human gastric disease signaled a medical revolution that has already significantly reduced the incidence of one major human disorder (duodenal ulcer disease) and also promises to decrease a global lethal malignancy (gastric cancer). The great leaps forward in understanding the mechanisms of $H$. pylori pathogenesis are redefining our understanding of bacterial ecology and homeostasis; however, we are still a long way away from completely understanding how $H$. pylori is associated with the host and the development of disease. Elucidating this conundrum faces a number of challenges that require a combination of global and more focused, indepth analyses. Monitoring the epigenetic changes occurring during infection, alongside more detailed analyses of the $H$. pylori-induced adaptive and innate immune responses may help to decipher the reasons for the failure of current vaccines. Given the increased incidence of antibiotic resistance, discovery of so far unknown bacterial virulence factors may potentially facilitate the development of new drugs. Moreover, in light of accumulating data showing that H. pylori infection could be beneficial for humans, we may need to rethink the commonly used medical approaches to treat $H$. pylori infections.

\section{References}

[1] M. Kidd and I. M. Modlin, "A century of Helicobacter pylori: paradigms lost-paradigms regained," Digestion, vol. 59, no. 1, pp. 1-15, 1998. 
[2] J. R. Warren, "Unidentified curved bacilli on gastric epithelium in active chronic gastritis," Lancet, vol. 1, no. 8336, pp. 1273-1275, 1983.

[3] B. J. Marshall, J. A. Armstrong, D. B. McGechie, and R. J. Glancy, "Attempt to fulfil Koch's postulates for pyloric campylobacter," Medical Journal of Australia, vol. 142, no. 8, pp. 436-439, 1985.

[4] A. Nomura, G. N. Stemmermann, P. H. Chyou, I. Kato, G. I. Perez-Perez, and M. J. Blaser, "Helicobacter pylori infection and gastric carcinoma among Japanese Americans in Hawaii," New England Journal of Medicine, vol. 325, no. 16, pp. 1132-1136, 1991.

[5] J. G. Kusters, A. H. M. van Vliet, and E. J. Kuipers, "Pathogenesis of Helicobacter pylori infection," Clinical Microbiology Reviews, vol. 19, no. 3, pp. 449-490, 2006.

[6] J. Parsonnet, G. D. Friedman, and D. P. Vandersteen, "Helicobacter pylori infection and the risk of gastric carcinoma," New England Journal of Medicine, vol. 325, no. 16, pp. 11271131, 1991.

[7] J. Parsonnet, S. Hansen, and L. Rodriguez, "Helicobacter pylori infection and gastric lymphoma," New England Journal of Medicine, vol. 330, no. 18, pp. 1267-1271, 1994.

[8] L. E. Hansson, L. Engstrand, and O. Nyren, "Helicobacter pylori infection: independent risk indicator of gastric adenocarcinoma," Gastroenterology, vol. 105, no. 4, pp. 1098-1103, 1993.

[9] P. J. Hu, H. M. Mitchell, Y. Y. Li, M. H. Zhou, and S. L. Hazell, "Association of Helicobacter pylori with gastric cancer and observations on the detection of this bacterium in gastric cancer cases," American Journal of Gastroenterology, vol. 89, no. 10, pp. 1806-1810, 1994.

[10] N. Uemura, S. Okamoto, and S. Yamamoto, "Helicobacter pylori infection and the development of gastric cancer," New England Journal of Medicine, vol. 345, no. 11, pp. 784-789, 2001.

[11] World Health Organisation, "Schistosomes, liver flukes and Helicobacter pylori. IARC Working Group on the Evaluation of Carcinogenic Risks to Humans. Lyon, 7-14 June 1994," IARC Monographs on the Evaluation of Carcinogenic Risks to Humans / World Health Organization, International Agency for Research on Cancer, vol. 61, pp. 1-241, 1994.

[12] B. Linz, F. Balloux, and Y. Moodley, "An African origin for the intimate association between humans and Helicobacter pylori," Nature, vol. 445, no. 7130, pp. 915-918, 2007.

[13] D. Falush, T. Wirth, and B. Linz, "Traces of human migrations in Helicobacter pylori populations," Science, vol. 299, no. 5612, pp. 1582-1585, 2003.

[14] Y. Moodley, B. Linz, Y. Yamaoka et al., "The peopling of the pacific from a bacterial perspective," Science, vol. 323, no. 5913, pp. 527-530, 2009.

[15] J. V. Solnick and D. B. Schauer, "Emergence of diverse Helicobacter species in the pathogenesis of gastric and enterohepatic diseases," Clinical Microbiology Reviews, vol. 14, no. 1, pp. 59-97, 2001.

[16] T. L. Cover and M. J. Blaser, "Helicobacter pylori in health and disease," Gastroenterology, vol. 136, no. 6, pp. 1863-1873, 2009.

[17] M. A. Al-Moagel, D. G. Evans, and M. E. Abdulghani, "Prevalence of Helicobacter (formerly Campylobacter) pylori infection in Saudia Arabia, and comparison of those with and without upper gastrointestinal symptoms," American Journal of Gastroenterology, vol. 85, no. 8, pp. 944-948, 1990.
[18] D. Y. Graham, M. F. Go, and D. J. Evans, "Review article: urease, gastric ammonium/ammonia, and Helicobacter pylori-the past, the present, and recommendations for future research," Alimentary Pharmacology and Therapeutics, vol. 6, no. 6, pp. 659-669, 1992.

[19] H. M. Malaty, "Epidemiology of Helicobacter pylori infection, best practice and research," Clinical Gastroenterology, vol. 21, no. 2, pp. 205-214, 2007.

[20] K. D. Crew and A. I. Neugut, "Epidemiology of gastric cancer," World Journal of Gastroenterology, vol. 12, no. 3, pp. 354-362, 2006.

[21] R. A. Feldman, A. J. P. Eccersley, and J. M. Hardie, "Epidemiology of Helicobacter pylori: acquisition, transmission, population prevalence and disease-to-infection ratio," British Medical Bulletin, vol. 54, no. 1, pp. 39-53, 1998.

[22] H. Malaty, H. M. T. El-Zimaity, R. M. Genta, R. A. Cole, and D. Y. Graham, "High-dose proton pump inhibitor plus amoxycillin for the treatment or retreatment of Helicobacter pylori infection," Alimentary Pharmacology and Therapeutics, vol. 10, no. 6, pp. 1001-1004, 1996.

[23] R. M. Peek and M. J. Blaser, "Helicobacter pylori and gastrointestinal tract adenocarcinomas," Nature Reviews Cancer, vol. 2, no. 1, pp. 28-37, 2002.

[24] M. Kurosawa, S. Kikuchi, Y. Inaba, T. Ishibashi, and F. Kobayashi, "Helicobacter pylori infection among Japanese children," Journal of Gastroenterology and Hepatology, vol. 15, no. 12, pp. 1382-1385, 2000.

[25] Y. Yamaoka, D. H. Kwon, and D. Y. Graham, "A M(r) 34000 proinflammatory outer membrane protein (OipA) of Helicobacter pylori," Proceedings of the National Academy of Sciences of the United States of America, vol. 97, no. 13, pp. 7533-7538, 2000.

[26] K. J. Goodman, P. Correa, H. J. Tenganá Aux et al., "Helicobacter pylori infection in the Colombian Andes: a population-based study of transmission pathways," American Journal of Epidemiology, vol. 144, no. 3, pp. 290-299, 1996.

[27] R. J. Hopkins, P. A. Vial, and C. Ferreccio, "Seroprevalence of Helicobacter pylori in chile: vegetables may serve as one route of transmission," Journal of Infectious Diseases, vol. 168, no. 1, pp. 222-226, 1993.

[28] P. D. Klein, R. Gilman, and R. Leon-Barua, "Water source as risk factor for Helicobacter pylori infection in Peruvian children," Lancet, vol. 337, no. 8756, pp. 1503-1506, 1991.

[29] M. P. Dore, A. R. Sepulveda, and H. El-Zimaity, "Isolation of helicobacter pylori from sheep-implications for transmission to humans," American Journal of Gastroenterology, vol. 96, no. 5, pp. 1396-1401, 2001.

[30] J. G. Fox, "Non-human reservoirs of Helicobacter pylori," Alimentary Pharmacology and Therapeutics, Supplement, vol. 9, no. 2, pp. 93-103, 1995.

[31] T. Kwok, S. Backert, H. Schwarz, J. Berger, and T. F. Meyer, "Specific entry of Helicobacter pylori into cultured gastric epithelial cells via a zipper-like mechanism," Infection and Immunity, vol. 70, no. 4, pp. 2108-2120, 2002.

[32] J. D. Oh, S. M. Karam, and J. I. Gordon, "Intracellular Helicobacter pylori in gastric epithelial progenitors," Proceedings of the National Academy of Sciences of the United States of America, vol. 102, no. 14, pp. 5186-5191, 2005.

[33] A. Özbek, E. Özbek, H. Dursun, Y. Kalkan, and T. Demirci, "Can Helicobacter pylori invade human gastric mucosa?: an in vivo study using electron microscopy, immunohistochemical methods, and real-time polymerase chain reaction," 
Journal of Clinical Gastroenterology, vol. 44, no. 6, pp. 416422, 2010.

[34] A. M. Petersen, J. Blom, L. P. Andersen, and K. A. Krogfelt, "Role of strain type, AGS cells and fetal calf serum in Helicobacter pylori adhesion and invasion assays," FEMS Immunology and Medical Microbiology, vol. 29, no. 1, pp. 5967, 2000.

[35] M. R. Terebiznik, C. L. Vazquez, and K. Torbicki, "Helicobacter pylori VacA toxin promotes bacterial intracellular survival in gastric epithelial cells," Infection and Immunity, vol. 74, no. 12, pp. 6599-6614, 2006.

[36] H. M. S. Algood and T. L. Cover, "Helicobacter pylori persistence: an overview of interactions between $\mathrm{H}$. pylori and host immune defenses," Clinical Microbiology Reviews, vol. 19, no. 4, pp. 597-613, 2006.

[37] N. J. Talley, J. E. Ormand, C. A. Frie, and A. R. Zinsmeister, "Stability of pH gradients in vivo across the stomach in Helicobacter pylori gastritis, dyspepsia, and health," American Journal of Gastroenterology, vol. 87, no. 5, pp. 590-594, 1992.

[38] J. V. Solnick, C. Josenhans, S. Suerbaum, L. S. Tompkins, and A. Labigne, "Construction and characterization of an isogenic urease-negative mutant of Helicobacter mustelae," Infection and Immunity, vol. 63, no. 9, pp. 3718-3721, 1995.

[39] G. Geis, H. Leying, S. Suerbaum, U. Mai, and W. Opferkuch, "Ultrastructure and chemical analysis of Campylobacter pylori flagella," Journal of Clinical Microbiology, vol. 27, no. 3, pp. 436-441, 1989.

[40] L. K. Sycuro, Z. Pincus, K. D. Gutierrez et al., "Peptidoglycan crosslinking relaxation promotes Helicobacter pylori's helical shape and stomach colonization," Cell, vol. 141, no. 5, pp. 822-833, 2010.

[41] R. Haas, T. F. Meyer, and J. P. M. Van Putten, "Aflagellated mutants of Helicobacter pylori generated by genetic transformation of naturalloy competent strains using transposon shuttle mutagenesis," Molecular Microbiology, vol. 8, no. 4, pp. 753-760, 1993.

[42] S. Suerbaum, "The complex flagella of gastric Helicobacter species," Trends in Microbiology, vol. 3, no. 5, pp. 168-170, 1995.

[43] K. A. Eaton, S. Suerbaum, C. Josenhans, and S. Krakowka, "Colonization of gnotobiotic piglets by Helicobacter pylori deficient in two flagellin genes," Infection and Immunity, vol. 64, no. 7, pp. 2445-2448, 1996.

[44] D. J. McGee, M. L. Langford, E. L. Watson, J. E. Carter, Y. T. Chen, and K. M. Ottemann, "Colonization and inflammation deficiencies in Mongolian gerbils infected by Helicobacter pylori chemotaxis mutants," Infection and Immunity, vol. 73, no. 3, pp. 1820-1827, 2005.

[45] S. R. Schreiber, M. Konradt, C. Groll et al., "The spatial orientation of Helicobacter pylori in the gastric mucus," Proceedings of the National Academy of Sciences of the United States of America, vol. 101, no. 14, pp. 5024-5029, 2004.

[46] M. A. Croxen, G. Sisson, R. Melano, and P. S. Hoffman, "The Helicobacter pylori chemotaxis receptor tlpB (HP0103) is required for $\mathrm{pH}$ taxis and for colonization of the gastric mucosa," Journal of Bacteriology, vol. 188, no. 7, pp. 26562665, 2006.

[47] V. Necchi, M. E. Candusso, and F. Tava, "Intracellular, intercellular, and stromal invasion of gastric mucosa, preneoplastic lesions, and cancer by Helicobacter pylori," Gastroenterology, vol. 132, no. 3, pp. 1009-1023, 2007.

[48] L. A. Noach, T. M. Rolf, and G. N. J. Tytgat, "Electron microscopic study of association between Helicobacter pylori and gastric and duodenal mucosa," Journal of Clinical Pathology, vol. 47, no. 8, pp. 699-704, 1994.

[49] A. Dossumbekova, C. Prinz, J. Mages et al., "Helicobacter pylori HopH (OipA) and bacterial pathogenicity: genetic and functional genomic analysis of hopH gene polymorphisms," Journal of Infectious Diseases, vol. 194, no. 10, pp. 1346-1355, 2006.

[50] D. Ilver, A. Arnqvist, J. Ögren et al., "Helicobacter pylori adhesin binding fucosylated histo-blood group antigens revealed by retagging," Science, vol. 279, no. 5349, pp. 373377, 1998.

[51] J. Mahdavi, B. Sondén, M. Hurtig et al., "Helicobacter pylori SabA adhesin in persistent infection and chronic inflammation," Science, vol. 297, no. 5581, pp. 573-578, 2002.

[52] B. Peck, M. Ortkamp, K. D. Diehl, E. Hundt, and B. Knapp, "Conservation, localization and expression of HopZ, a protein involved in adhesion of Helicobacter pylori," Nucleic Acids Research, vol. 27, no. 16, pp. 3325-3333, 1999.

[53] M. Aspholm-Hurtig, G. Dailide, M. Lahmann et al., "Functional adaptation of BabA the $\mathrm{H}$. pylori $\mathrm{ABO}$ blood group antigen binding adhesin," Science, vol. 305, no. 5683, pp. 519522, 2004.

[54] A. Bäckström, C. Lundberg, D. Kersulyte, D. E. Berg, T. Borén, and A. Arnqvist, "Metastability of Helicobacter pylori bab adhesin genes and dynamics in Lewis b antigen binding," Proceedings of the National Academy of Sciences of the United States of America, vol. 101, no. 48, pp. 16923-16928, 2004.

[55] J. V. Solnick, L. M. Hansen, N. R. Salama, J. K. Boonjakuakul, and M. Syvanen, "Modification of Helicobacter pylori outer membrane protein expression during experimental infection of rhesus macaques," Proceedings of the National Academy of Sciences of the United States of America, vol. 101, no. 7, pp. 2106-2111, 2004.

[56] C. Petersson, M. Forsberg, M. Aspholm et al., "Helicobacter pylori SabA adhesin evokes a strong inflammatory response in human neutrophils which is down-regulated by the neutrophil-activating protein," Medical Microbiology and Immunology, vol. 195, no. 4, pp. 195-206, 2006.

[57] S. Tan, L. S. Tompkins, and M. R. Amieva, "Helicobacter pylori usurps cell polarity to turn the cell surface into a replicative niche," PLoS Pathogens, vol. 5, no. 5, Article ID e1000407, 2009.

[58] R. Battan, M. C. Raviglione, A. Palagiano et al., "Helicobacter pylori infection in patients with acquired immune deficiency syndrome," American Journal of Gastroenterology, vol. 85, no. 12, pp. 1576-1579, 1990.

[59] K. B. Bamford, X. Fan, S. E. Crowe et al., "Lymphocytes in the human gastric mucosa during Helicobacter pylori have a T helper cell 1 phenotype," Gastroenterology, vol. 114, no. 3, pp. 482-492, 1998.

[60] A. Muotiala, I. M. Helander, L. Pyhala, T. U. Kosunen, and A. P. Moran, "Low biological activity of Helicobacter pylori lipopolysaccharide," Infection and Immunity, vol. 60, no. 4, pp. 1714-1716, 1992.

[61] P. M. Lepper, M. Triantafilou, C. Schumann, E. M. Schneider, and K. Triantafilou, "Lipopolysaccharides from Helicobacter pylori can act as antagonists for Toll-like receptor 4," Cellular Microbiology, vol. 7, no. 4, pp. 519-528, 2005.

[62] A. P. Moran, B. Lindner, and E. J. Walsh, "Structural characterization of the lipid A component of Helicobacter pylori rough- and smooth-form lipopolysaccharides," Journal of Bacteriology, vol. 179, no. 20, pp. 6453-6463, 1997. 
[63] G. O. Aspinall and M. A. Monteiro, "Lipopolysaccharides of Helicobacter pylori strains P466 and MO19: structures of the $\mathrm{O}$ antigen and core oligosaccharide regions," Biochemistry, vol. 35, no. 7, pp. 2498-2504, 1996.

[64] B. J. Appelmelk, I. Simoons-Smit, R. Negrini et al., "Potential role of molecular mimicry between Helicobacter pylori lipopolysaccharide and host Lewis blood group antigens in autoimmunity," Infection and Immunity, vol. 64, no. 6, pp. 2031-2040, 1996.

[65] C. Wunder, Y. Churin, and F. Winau, "Cholesterol glucosylation promotes immune evasion by Helicobacter pylori," Nature Medicine, vol. 12, no. 9, pp. 1030-1038, 2006.

[66] M. Ringnér, K. H. Valkonen, and T. Wadström, "Binding of vitronectin and plasminogen to Helicobacter pylori," FEMS Immunology and Medical Microbiology, vol. 9, no. 1, pp. 2934, 1994.

[67] E. Andersen-Nissen, K. D. Smith, K. L. Strobe et al., "Evasion of Toll-like receptor 5 by flagellated bacteria," Proceedings of the National Academy of Sciences of the United States of America, vol. 102, no. 26, pp. 9247-9252, 2005.

[68] A. T. Gewirtz, Y. Yu, U. S. Krishna, D. A. Israel, S. L. Lyons, and R. M. Peek, "Helicobacter pylori flagellin evades toll-like receptor 5-mediated innate immunity," Journal of Infectious Diseases, vol. 189, no. 10, pp. 1914-1920, 2004.

[69] S. K. Lee, A. Stack, E. Katzowitsch, S. I. Aizawa, S. Suerbaum, and C. Josenhans, "Helicobacter pylori flagellins have very low intrinsic activity to stimulate human gastric epithelial cells via TLR5," Microbes and Infection, vol. 5, no. 15, pp. 1345-1356, 2003.

[70] B. Gebert, W. Fischer, E. Weiss, R. Hoffmann, and R. Haas, "Helicobacter pylori vacuolating cytotoxin inhibits $\mathrm{T}$ lymphocyte activation," Science, vol. 301, no. 5636, pp. 10991102, 2003.

[71] V. J. Torres, S. E. VanCompernolle, M. S. Sundrud, D. Unutmaz, and T. L. Cover, "Helicobacter pylori vacuolating cytotoxin inhibits activation-induced proliferation of human T and B lymphocyte subsets," Journal of Immunology, vol. 179, no. 8, pp. 5433-5440, 2007.

[72] R. J. Menaker, P. J. M. Ceponis, and N. L. Jones, "Helicobacter pylori induces apoptosis of macrophages in association with alterations in the mitochondrial pathway," Infection and Immunity, vol. 72, no. 5, pp. 2889-2898, 2004.

[73] P. Y. Zheng and N. L. Jones, "Helicobacter pylori strains expressing the vacuolating cytotoxin interrupt phagosome maturation in macrophages by recruiting and retaining TACO (coronin 1) protein," Cellular Microbiology, vol. 5, no. 1, pp. 25-40, 2003.

[74] C. Schmees, C. Prinz, T. Treptau et al., "Inhibition of Tcell proliferation by Helicobacter pylori gamma-glutamyl transpeptidase," Gastroenterology, vol. 132, no. 5, pp. 1820 1833, 2007.

[75] J. Zabaleta, D. J. McGee, A. H. Zea et al., "Helicobacter pylori arginase inhibits $\mathrm{T}$ cell proliferation and reduces the expression of the TCR zeta-chain (CD3zeta)," Journal of Immunology, vol. 173, no. 1, pp. 586-593, 2004.

[76] A. P. Gobert, D. J. McGee, M. Akhtar et al., "Helicobacter pylori arginase inhibits nitric oxide production by eukaryotic cells: a strategy for bacterial survival," Proceedings of the National Academy of Sciences of the United States of America, vol. 98, no. 24, pp. 13844-13849, 2001.

[77] J. Yuan, P. Li, J. Tao et al., "H. pylori escape host immunoreaction through inhibiting ILK expression by VacA," Cellular and Molecular Immunology, vol. 6, no. 3, pp. 191-197, 2009.
[78] N. Akopyanz, N. O. Bukanov, T. U. Westblom, S. Kresovich, and D. E. Berg, "DNA diversity among clinical isolates of helicobacter pylori detected by PCR-based RAPD fingerprinting," Nucleic Acids Research, vol. 20, no. 19, pp. 51375142, 1992.

[79] I. Kansau, J. Raymond, and E. Bingen, "Genotyping of Helicobacter pylori isolates by sequencing of PCR products and comparison with the RAPD technique," Research in Microbiology, vol. 147, no. 8, pp. 661-669, 1996.

[80] S. Miehlke, R. M. Genta, D. Y. Graham, and M. F. Go, "Molecular relationships of Helicobacter pylori strains in a family with gastroduodenal disease," American Journal of Gastroenterology, vol. 94, no. 2, pp. 364-368, 1999.

[81] B. Björkholm, M. Sjölund, P. G. Falk, O. G. Berg, L. Engstrand, and D. I. Andersson, "Mutation frequency and biological cost of antibiotic resistance in Helicobacter pylori," Proceedings of the National Academy of Sciences of the United States of America, vol. 98, no. 25, pp. 14607-14612, 2001.

[82] S. Suerbaum and C. Josenhans, "Helicobacter pylori evolution and phenotypic diversification in a changing host," Nature Reviews Microbiology, vol. 5, no. 6, pp. 441-452, 2007.

[83] J. F. Tomb, O. White, A. R. Kerlavage et al., "The complete genome sequence of the gastric pathogen Helicobacter pylori," Nature, vol. 388, no. 6642, pp. 539-547, 1997.

[84] B. D. Robertson and T. F. Meyer, "Genetic variation in pathogenic bacteria," Trends in Genetics, vol. 8, no. 12, pp. 422-427, 1992.

[85] L. Salaün, B. Linz, S. Suerbaum, and N. J. Saunders, "The diversity within an expanded and redefined repertoire of phase-variable genes in Helicobacter pylori," Microbiology, vol. 150, no. 4, pp. 817-830, 2004.

[86] N. J. Saunders, J. F. Peden, D. W. Hood, and E. R. Moxon, "Simple sequence repeats in the Helicobacter pylori genome," Molecular Microbiology, vol. 27, no. 6, pp. 1091-1098, 1998.

[87] M. Pérez-Losada, E. B. Browne, A. Madsen, T. Wirth, R. P. Viscidi, and K. A. Crandall, "Population genetics of microbial pathogens estimated from multilocus sequence typing (MLST) data," Infection, Genetics and Evolution, vol. 6, no. 2, pp. 97-112, 2006.

[88] M. S. Dorer, J. Fero, and N. R. Salama, "DNA damage triggers genetic exchange in Helicobacter pylori," PLoS Pathogens, vol. 6, no. 7, Article ID e1001026, pp. 1-10, 2010.

[89] D. N. Baldwin, B. Shepherd, and P. Kraemer, "Identification of Helicobacter pylori genes that contribute to stomach colonization," Infection and Immunity, vol. 75, no. 2, pp. 1005-1016, 2007.

[90] D. M. Parkin, F. Bray, J. Ferlay, and P. Pisani, "Global cancer statistics, 2002," CA: A Cancer Journal for Clinicians, vol. 55, no. 2, pp. 74-108, 2002.

[91] World Health Organization, "Disease and injury country estimates," 2009.

[92] P. Bertuccio, L. Chatenoud, and F. Levi, "Recent patterns in gastric cancer: a global overview," International Journal of Cancer, vol. 125, no. 3, pp. 666-673, 2009.

[93] P. Lauren, "The two histological main types of gastric carcinoma: diffuse and so-called intestinal-type carcinoma. An attempt at a histo-clinical classification," Acta Pathologica et Microbiologica Scandinavica, vol. 64, pp. 31-49, 1965.

[94] D. B. Polk and R. M. Peek, "Helicobacter pylori: gastric cancer and beyond," Nature Reviews Cancer, vol. 10, no. 6, pp. 403-414, 2010.

[95] P. Correa, "Diet modification and gastric cancer prevention," Journal of the National Cancer Institute. Monographs, vol. 12, no. 12, pp. 75-78, 1992. 
[96] J. L. Telford, A. Covacci, R. Rappuoli, and P. Chiara, "Immunobiology of Helicobacter pylori infection," Current Opinion in Immunology, vol. 9, no. 4, pp. 498-503, 1997.

[97] J. H. Kurata and B. M. Haile, "Epidemiology of peptic ulcer disease," Clinics in Gastroenterology, vol. 13, no. 2, pp. 289307, 1984.

[98] S. J. van Zanten, M. F. Dixon, and A. Lee, "The gastric transitional zones: neglected links between gastroduodenal pathology and Helicobacter ecology," Gastroenterology, vol. 116, no. 5, pp. 1217-1229, 1999.

[99] L. A. García Rodríguez and L. Barreales Tolosa, "Risk of upper gastrointestinal complications among users of traditional NSAIDs and COXIBs in the general population," Gastroenterology, vol. 132, no. 2, pp. 498-506, 2007.

[100] S. Take, M. Mizuno, K. Ishiki et al., "The effect of eradicating Helicobacter pylori on the development of gastric cancer in patients with peptic ulcer disease," American Journal of Gastroenterology, vol. 100, no. 5, pp. 1037-1042, 2005.

[101] C. Holcombe, "Helicobacter pylori: the African enigma," Gut, vol. 33, no. 4, pp. 429-431, 1992.

[102] R. Ally, H. M. Mitchell, and I. Segal, "Differences in the immune response to H. pylori infection in Sowetan subjects may relate to concurrent parasitic infections," South African Medical Journal, vol. 90, p. 642, 2000.

[103] J. G. Fox, P. Beck, C. A. Dangler et al., "Concurrent enteric helminth infection modulates inflammation and gastric immune responses and reduces helicobacter-induced gastric atrophy," Nature Medicine, vol. 6, no. 5, pp. 536-542, 2000.

[104] R. D. Leunk, P. T. Johnson, B. C. David, W. G. Kraft, and D. R. Morgan, "Cytotoxic activity in broth-culture filtrates of Campylobacter pylori," Journal of Medical Microbiology, vol. 26, no. 2, pp. 93-99, 1988.

[105] M. Gerhard, N. Lehn, N. Neumayer et al., "Clinical relevance of the Helicobacter pylori gene for blood-group antigenbinding adhesin," Proceedings of the National Academy of Sciences of the United States of America, vol. 96, no. 22, pp. 12778-12783, 1999.

[106] L. J. Van Doorn, C. Figueiredo, R. Sanna et al., "Clinical relevance of the cagA, vacA, and iceA status of Helicobacter pylori," Gastroenterology, vol. 115, no. 1, pp. 58-66, 1998.

[107] R. A. Alm, L. S. L. Ling, D. T. Moir et al., "Genomic-sequence comparison of two unrelated isolates of the human gastric pathogen Helicobacter pylori," Nature, vol. 397, no. 6715, pp. 176-180, 1999.

[108] J. C. Atherton, “H. pylori virulence factors," British Medical Bulletin, vol. 54, no. 1, pp. 105-120, 1998.

[109] M. Rohde, J. Püls, R. Buhrdorf, W. Fischer, and R. Haas, "A novel sheathed surface organelle of the Helicobacter pylori cag type IV secretion system," Molecular Microbiology, vol. 49, no. 1, pp. 219-234, 2003.

[110] J. Tanaka, T. Suzuki, H. Mimuro, and C. Sasakawa, "Structural definition on the surface of Helicobacter pylori type IV secretion apparatus," Cellular Microbiology, vol. 5, no. 6, pp. 395-404, 2003.

[111] T. Kubori, Y. Matsushima, and D. Nakamura, "Supramolecular structure of the salmonella typhimurium type III protein secretion system," Science, vol. 280, no. 5363, pp. 602-605, 1998.

[112] S. Odenbreit, J. Püls, B. Sedlmaier, E. Gerland, W. Fischer, and R. Haas, "Translocation of Helicobacter pylori CagA into gastric epithelial cells by type IV secretion," Science, vol. 287, no. 5457, pp. 1497-1500, 2000.

[113] B. Bauer, S. Moese, S. Bartfeld, T. F. Meyer, and M. Selbach, "Analysis of cell type-specific responses mediated by the type
IV secretion system of Helicobacter pylori," Infection and Immunity, vol. 73, no. 8, pp. 4643-4652, 2005.

[114] A. Olofsson, A. Vallström, K. Petzold et al., "Biochemical and functional characterization of Helicobacter pylori vesicles," Molecular Microbiology, vol. 77, no. 6, pp. 1539-1555, 2010.

[115] T. Kwok, D. Zabler, S. Urman et al., "Helicobacter exploits integrin for type IV secretion and kinase activation," Nature, vol. 449, no. 7164, pp. 862-866, 2007.

[116] L. F. Jiménez-Soto, S. Kutter, and X. Sewald, "Helicobacter pylori type IV secretion apparatus exploits $\beta 1$ integrin in a novel RGD-independent manner," PLoS Pathogens, vol. 5, no. 12, Article ID e1000684, 2009.

[117] A. Saha, S. Backert, C. E. Hammond, M. Gooz, and A. J. Smolka, "Helicobacter pylori CagL activates ADAM17 to induce repression of the gastric H, K-ATPase $\alpha$ subunit," Gastroenterology, vol. 139, no. 1, pp. 239-248, 2010.

[118] C. Weydig, A. Starzinski-Powitz, G. Carra, J. Löwer, and S. Wessler, "CagA-independent disruption of adherence junction complexes involves E-cadherin shedding and implies multiple steps in Helicobacter pylori pathogenicity," Experimental Cell Research, vol. 313, no. 16, pp. 3459-3471, 2007.

[119] A. M. Y. Nomura, J. Lee, G. N. Stemmermann, R. Y. Nomura, G. I. Perez-Perez, and M. J. Blaser, "Helicobacter pylori CagA seropositivity and gastric carcinoma risk in a Japanese American population," Journal of Infectious Diseases, vol. 186, no. 8, pp. 1138-1144, 2002.

[120] M. J. Blaser, G. I. Perez-Perez, H. Kleanthous et al., "Infection with Helicobacter pylori strains possessing cagA is associated with an increased risk of developing adenocarcinoma of the stomach," Cancer Research, vol. 55, no. 10, pp. 2111-2115, 1995.

[121] A. H. Wu, J. E. Crabtree, L. Bernstein et al., "Role of Helicobacter pylori CagA+ strains and risk of adenocarcinoma of the stomach and esophagus," International Journal of Cancer, vol. 103, no. 6, pp. 815-821, 2003.

[122] N. Ohnishi, H. Yuasa, S. Tanaka et al., "Transgenic expression of Helicobacter pylori CagA induces gastrointestinal and hematopoietic neoplasms in mouse," Proceedings of the National Academy of Sciences of the United States of America, vol. 105, no. 3, pp. 1003-1008, 2008.

[123] H. Mimuro, T. Suzuki, S. Nagai et al., "Helicobacter pylori dampens gut epithelial self-renewal by inhibiting apoptosis, a bacterial strategy to enhance colonization of the stomach," Cell Host and Microbe, vol. 2, no. 4, pp. 250-263, 2007.

[124] B. Bauer, S. Bartfeld, and T. F. Meyer, "H. pylori selectively blocks EGFR endocytosis via the non-receptor kinase c-Abl and CagA," Cellular Microbiology, vol. 11, no. 1, pp. 156-169, 2009.

[125] S. Brandt, T. Kwok, R. Hartig, W. König, and S. Backert, "NF-kappaB activation and potentiation of proinflammatory responses by the Helicobacter pylori CagA protein," Proceedings of the National Academy of Sciences of the United States of America, vol. 102, no. 26, pp. 9300-9305, 2005.

[126] D. M. Bronte-Tinkew, M. Terebiznik, and A. Franco, "Helicobacter pylori cytotoxin-associated gene a activates the signal transducer and activator of transcription 3 pathway in vitro and in vivo," Cancer Research, vol. 69, no. 2, pp. 632639, 2009.

[127] N. Murata-Kamiya, K. Kikuchi, T. Hayashi, H. Higashi, and M. Hatakeyama, "Helicobacter pylori exploits host membrane phosphatidylserine for delivery, localization, and pathophysiological action of the CagA oncoprotein," Cell Host and Microbe, vol. 7, no. 5, pp. 399-411, 2010. 
[128] M. Stein, R. Rappuoli, and A. Covacci, "Tyrosine phosphorylation of the Helicobacter pylori CagA antigen after cagdriven host cell translocation," Proceedings of the National Academy of Sciences of the United States of America, vol. 97, no. 3, pp. 1263-1268, 2000.

[129] M. Asahi, T. Azuma, and S. Ito, "Helicobacter pylori CagA protein can be tyrosine phosphorylated in gastric epithelial cells," Journal of Experimental Medicine, vol. 191, no. 4, pp. 593-602, 2000.

[130] M. Selbach, S. Moese, C. R. Hauck, T. F. Meyer, and S. Backert, "Src is the kinase of the Helicobacter pylori CagA protein in vitro and in vivo," Journal of Biological Chemistry, vol. 277, no. 9, pp. 6775-6778, 2002.

[131] M. Poppe, S. M. Feller, G. Römer, and S. Wessler, "Phosphorylation of Helicobacter pylori CagA by c-Abl leads to cell motility," Oncogene, vol. 26, no. 24, pp. 3462-3472, 2007.

[132] M. Selbach, S. Moese, R. Hurwitz, C. R. Hauck, T. F. Meyer, and S. Backert, "The Helicobacter pylori CagA protein induces cortactin dephosphorylation and actin rearrangement by c-Src inactivation," EMBO Journal, vol. 22, no. 3, pp. 515-528, 2003.

[133] I. Tammer, S. Brandt, R. Hartig, W. König, and S. Backert, "Activation of Abl by Helicobacter pylori: a novel kinase for CagA and crucial mediator of host cell scattering," Gastroenterology, vol. 132, no. 4, pp. 1309-1319, 2007.

[134] M. Hatakeyama, "SagA of CagA in Helicobacter pylori pathogenesis," Current Opinion in Microbiology, vol. 11, no. 1, pp. 30-37, 2008.

[135] M. Stein, F. Bagnoli, R. Halenbeck, R. Rappuoli, W. J. Fantl, and A. Covacci, "c-Src/Lyn kinases activate Helicobacter pylori CagA through tyrosine phosphorylation of the EPIYA motifs," Molecular Microbiology, vol. 43, no. 4, pp. 971-980, 2002.

[136] K. R. Jones, Y. M. Joo, S. Jang et al., "Polymorphism in the cagA EPIYA motif impacts development of gastric cancer," Journal of Clinical Microbiology, vol. 47, no. 4, pp. 959-968, 2009.

[137] H. Higashi, R. Tsutsumi, S. Muto et al., "SHP-2 tyrosine phosphatase as an intracellular target of Helicobacter pylori CagA protein," Science, vol. 295, no. 5555, pp. 683-686, 2002.

[138] E. D. Segal, J. Cha, J. Lo, S. Falkow, and L. S. Tompkins, "Altered states: involvement of phosphorylated CagA in the induction of host cellular growth changes by Helicobacter pylori," Proceedings of the National Academy of Sciences of the United States of America, vol. 96, no. 25, pp. 14559-14564, 1999.

[139] M. Naito, T. Yamazaki, R. Tsutsumi et al., "Influence of EPIYA-repeat polymorphism on the phosphorylationdependent biological activity of Helicobacter pylori CagA," Gastroenterology, vol. 130, no. 4, pp. 1181-1190, 2006.

[140] S. Backert, N. Tegtmeyer, and M. Selbach, "The versatility of helicobacter pylori Cag A effector protein functions: the master key hypothesis," Helicobacter, vol. 15, no. 3, pp. 163176, 2010.

[141] M. R. Amieva, R. Vogetmann, A. Covacci, L. S. Tompkins, W. J. Nelson, and S. Falkow, "Disruption of the epithelial apicaljunctional complex by Helicobacter pylori CagA," Science, vol. 300, no. 5624, pp. 1430-1434, 2003.

[142] I. Saadat, H. Higashi, and C. Obuse, "Helicobacter pylori CagA targets PAR1/MARK kinase to disrupt epithelial cell polarity," Nature, vol. 447, no. 7142, pp. 330-333, 2007.

[143] S. Ren, H. Higashi, H. Lu, T. Azuma, and M. Hatakeyama, "Structural basis and functional consequence of Helicobacter pylori cagA multimerization in cells," Journal of Biological Chemistry, vol. 281, no. 43, pp. 32344-32352, 2006.

[144] D. Nesić, M. C. Miller, Z. T. Quinkert, M. Stein, B. T. Chait, and C. E. Stebbins, "Helicobacter pylori CagA inhibits PAR1MARK family kinases by mimicking host substrates," Nature Structural and Molecular Biology, vol. 17, no. 1, pp. 130-132, 2010.

[145] D. Wu and W. Pan, "GSK3: a multifaceted kinase in Wnt signaling," Trends in Biochemical Sciences, vol. 35, no. 3, pp. 161-168, 2010.

[146] A. T. Franco, D. A. Israel, M. K. Washington et al., "Activation of $\beta$-catenin by carcinogenic Helicobacter pylori," Proceedings of the National Academy of Sciences of the United States of America, vol. 102, no. 30, pp. 10646-10651, 2005.

[147] N. Murata-Kamiya, Y. Kurashima, Y. Teishikata et al., "Helicobacter pylori CagA interacts with E-cadherin and deregulates the $\beta$-catenin signal that promotes intestinal transdifferentiation in gastric epithelial cells," Oncogene, vol. 26, no. 32, pp. 4617-4626, 2007.

[148] M. Suzuki, H. Mimuro, T. Suzuki, M. Park, T. Yamamoto, and C. Sasakawa, "Interaction of CagA with Crk plays an important role in Helicobacter pylori-induced loss of gastric epithelial cell adhesion," Journal of Experimental Medicine, vol. 202, no. 9, pp. 1235-1247, 2005.

[149] O. Sokolova, P. M. Bozko, and M. Naumann, "Helicobacter pylori suppresses glycogen synthase kinase $3 \beta$ to promote $\beta$ catenin activity," Journal of Biological Chemistry, vol. 283, no. 43, pp. 29367-29374, 2008.

[150] V. Ricci, C. Ciacci, R. Zarrilli et al., "Effect of Helicobacter pylori on gastric epithelial cell migration and proliferation in vitro: role of VacA and CagA," Infection and Immunity, vol. 64, no. 7, pp. 2829-2833, 1996.

[151] S. A. Sharma, M. K. R. Tummuru, M. J. Blaser, and L. D. Kerr, "Activation of IL-8 gene expression by Helicobacter pylori is regulated by transcription factor nuclear factor-kappa B in gastric epithelial cells," Journal of Immunology, vol. 160, no. 5, pp. 2401-2407, 1998.

[152] A. Bhattacharyya, S. Pathak, S. Datta, S. Chattopadhyay, J. Basu, and M. Kundu, "Mitogen-activated protein kinases and nuclear factor- $\kappa \mathrm{B}$ regulate Helicobacter pylori-mediated interleukin-8 release from macrophages," Biochemical Journal, vol. 368, no. 1, pp. 121-129, 2002.

[153] M. Naumann, S. Wessler, C. Bartsch et al., "Activation of activator protein 1 and stress response kinases in epithelial cells colonized by Helicobacter pylori encoding the cag pathogenicity island," Journal of Biological Chemistry, vol. 274, no. 44, pp. 31655-31662, 1999.

[154] C. C. Allison, T. A. Kufer, E. Kremmer, M. Kaparakis, and R. L. Ferrero, "Helicobacter pylori induces MAPK phosphorylation and AP-1 activation via a NOD1-dependent mechanism," Journal of Immunology, vol. 183, no. 12, pp. 8099-8109, 2009.

[155] J. Viala, C. Chaput, I. G. Boneca et al., "Nod1 responds to peptidoglycan delivered by the Helicobacter pylori cag pathogenicity island," Nature Immunology, vol. 5, no. 11, pp. 1166-1174, 2004.

[156] M. L. Hutton, M. Kaparakis-Liaskos, L. Turner, A. Cardona, T. Kwok, and R. L. Ferrero, "Helicobacter pylori exploits cholesterol-rich microdomains for induction of NF- $\kappa \mathrm{B}$ dependent responses and peptidoglycan delivery in epithelial cells," Infection and Immunity, vol. 78, no. 11, pp. 4523-4531, 2010 . 
[157] M. Kaparakis, L. Turnbull, L. Carneiro et al., "Bacterial membrane vesicles deliver peptidoglycan to NOD1 in epithelial cells," Cellular Microbiology, vol. 12, no. 3, pp. 372-385, 2010.

[158] S.-Y. Kim, Y.-C. Lee, H. K. Kim, and M. J. Blaser, "Helicobacter pylori CagA transfection of gastric epithelial cells induces interleukin-8," Cellular Microbiology, vol. 8, no. 1, pp. 97106, 2006.

[159] V. Necchi, P. Sommi, V. Ricci, and E. Solcia, "In vivo accumulation of Helicobacter pylori products, NOD1, ubiquitinated proteins and proteasome in a novel cytoplasmic structure," PloS One, vol. 5, no. 3, article e9716, 2010.

[160] A. T. Franco, D. B. Friedman, T. A. Nagy et al., "Delineation of a carcinogenic Helicobacter pylori proteome," Molecular and Cellular Proteomics, vol. 8, no. 8, pp. 1947-1958, 2009.

[161] A. Wada, E. Yamasaki, and T. Hirayama, "Helicobacter pylori vacuolating cytotoxin, VacA, is responsible for gastric ulceration," Journal of Biochemistry, vol. 136, no. 6, pp. 741746, 2004

[162] M. Molinari, C. Galli, N. Norais et al., "Vacuoles induced by Helicobacter pylori toxin contain both late endosomal and lysosomal markers," Journal of Biological Chemistry, vol. 272, no. 40, pp. 25339-25344, 1997.

[163] E. Papini, M. De Bernard, E. Milia et al., "Cellular vacuoles induced by Helicobacter pylori originate from late endosomal compartments," Proceedings of the National Academy of Sciences of the United States of America, vol. 91, no. 21, pp. 9720-9724, 1994.

[164] Y. Li, A. Wandinger-Ness, J. R. Goldenring, and T. L. Cover, "Clustering and redistribution of late endocytic compartments in response to Helicobacter pylori vacuolating toxin," Molecular Biology of the Cell, vol. 15, no. 4, pp. 1946-1959, 2004.

[165] T. L. Cover and S. R. Blanke, "Helicobacter pylori VacA, a paradigm for toxin multifunctionality," Nature Reviews Microbiology, vol. 3, no. 4, pp. 320-332, 2005.

[166] J. C. Atherton, P. Cao, R. M. Peek, M. K. R. Tummuru, M. J. Blaser, and T. L. Cover, "Mosaicism in vacuolating cytotoxin alleles of helicobacter pylori. Association of specific vacA types with cytotoxin production and peptic ulceration," Journal of Biological Chemistry, vol. 270, no. 30, pp. 1777117777, 1995.

[167] C. Figueiredo, J. C. Machado, P. Pharoah et al., "Helicobacter pylori and interleukin 1 genotyping: an opportunity to identify high-risk individuals for gastric carcinoma," Journal of the National Cancer Institute, vol. 94, no. 22, pp. 16801687, 2002.

[168] L. J. Van Doorn, C. Figueiredo, F. Megraud et al., "Geographic distribution of vacA allelic types of Helicobacter pylori," Gastroenterology, vol. 116, no. 4, pp. 823-830, 1999.

[169] J. L. Telford, P. Ghiara, M. Dell'Orco et al., "Gene structure of the Helicobacter pylori cytotoxin and evidence of its key role in gastric disease," Journal of Experimental Medicine, vol. 179, no. 5, pp. 1653-1658, 1994.

[170] K. Ogura, S. Maeda, M. Nakao et al., "Virulence factors of Helicobacter pylori responsible for gastric diseases in Mongolian gerbil," Journal of Experimental Medicine, vol. 192, no. 11, pp. 1601-1609, 2000.

[171] T. L. Cover and M. J. Blaser, "Purification and characterization of the vacuolating toxin from Helicobacter pylori," Journal of Biological Chemistry, vol. 267, no. 15, pp. 1057010575, 1992.

[172] W. Fischer, R. Buhrdorf, E. Gerland, and R. Haas, "Outer membrane targeting of passenger proteins by the vacuolating cytotoxin autotransporter of Helicobacter pylori," Infection and Immunity, vol. 69, no. 11, pp. 6769-6775, 2001.

[173] D. Ilver, S. Barone, D. Mercati, P. Lupetti, and J. L. Telford, "Helicobacter pylori toxin VacA is transferred to host cells via a novel contact-dependent mechanism," Cellular Microbiology, vol. 6, no. 2, pp. 167-174, 2004.

[174] P. Lupetti, J. E. Heuser, and R. Manetti, "Oligomeric and subunit structure of the Helicobacter pylori vacuolating cytotoxin," Journal of Cell Biology, vol. 133, no. 4, pp. 801807, 1996.

[175] M. S. McClain, H. Iwamoto, P. Cao et al., "Essential role of a GXXXG motif for membrane channel formation by Helicobacter pylori vacuolating toxin," Journal of Biological Chemistry, vol. 278, no. 14, pp. 12101-12108, 2003.

[176] A. D. Vinion-Dubiel, M. S. McClain, D. M. Czajkowsky et al., "A dominant negative mutant of Helicobacter pylori vacuolating toxin (VacA) inhibits VacA-induced cell vacuolation," Journal of Biological Chemistry, vol. 274, no. 53, pp. 3773637742, 1999.

[177] D. Ye, D. C. Willhite, and S. R. Blanke, "Identification of the minimal intracellular vacuolating domain of the Helicobacter pylori vacuolating toxin," Journal of Biological Chemistry, vol. 274, no. 14, pp. 9277-9282, 1999.

[178] J. A. Garner and T. L. Cover, "Binding and internalization of the Helicobacter pylori vacuolating cytotoxin by epithelial cells," Infection and Immunity, vol. 64, no. 10, pp. 4197-4203, 1996.

[179] K. Yahiro, T. Niidome, M. Kimura et al., "Activation of Helicobacter pylori VacA toxin by alkaline or acid conditions increases its binding to a $250-\mathrm{kDa}$ receptor protein-tyrosine phosphatase $\beta$," Journal of Biological Chemistry, vol. 274, no. 51, pp. 36693-36699, 1999.

[180] E. E. Hennig, M. M. Godlewski, E. Butruk, and J. Ostrowski, "Helicobacter pylori VacA cytotoxin interacts with fibronectin and alters HeLa cell adhesion and cytoskeletal organization in vitro," FEMS Immunology and Medical Microbiology, vol. 44, no. 2, pp. 143-150, 2005.

[181] K. Seto, Y. Hayashi-Kuwabara, T. Yoneta, H. Suda, and H. Tamaki, "Vacuolation induced by cytotoxin from Helicobacter pylori is mediated by the EGF receptor in HeLa cells," FEBS Letters, vol. 431, no. 3, pp. 347-350, 1998.

[182] X. Sewald, B. Gebert-Vogl, S. Prassl et al., "Integrin subunit CD18 Is the T-lymphocyte receptor for the Helicobacter pylori vacuolating cytotoxin," Cell Host and Microbe, vol. 3, no. 1, pp. 20-29, 2008.

[183] M. Molinari, C. Galli, M. De Bernard et al., "The acid activation of Helicobacter pylori toxin VacA: structural and membrane binding studies," Biochemical and Biophysical Research Communications, vol. 248, no. 2, pp. 334-340, 1998.

[184] V. R. Gupta, H. K. Patel, S. S. Kostolansky, R. A. Ballivian, J. Eichberg, and S. R. Blanke, "Sphingomyelin functions as a novel receptor for Helicobacter pylori VacA," PLoS Pathogens, vol. 4, no. 5, Article ID e1000073, 2008.

[185] T. L. Cover, U. S. Krishna, D. A. Israel, and R. M. Peek, "Induction of gastric epithelial cell apoptosis by Helicobacter pylori vacuolating cytotoxin," Cancer Research, vol. 63, no. 5, pp. 951-957, 2003.

[186] D. C. Willhite and S. R. Blanke, "Helicobacter pylori vacuolating cytotoxin enters cells, localizes to the mitochondria, and induces mitochondrial membrane permeability changes correlated to toxin channel activity," Cellular Microbiology, vol. 6, no. 2, pp. 143-154, 2004. 
[187] A. Galmiche, J. Rassow, A. Doye et al., "The N-terminal 34 $\mathrm{kDa}$ fragment of Helicobacter pylori vacuolating cytotoxin targets mitochondria and induces cytochrome c release," EMBO Journal, vol. 19, no. 23, pp. 6361-6370, 2000.

[188] D. C. Willhite, T. L. Cover, and S. R. Blanke, "Cellular vacuolation and mitochondrial cytochrome $c$ release are independent outcomes of Helicobacter pylori vacuolating cytotoxin activity that are each dependent on membrane channel formation," Journal of Biological Chemistry, vol. 278, no. 48, pp. 48204-48209, 2003.

[189] A. Oldani, M. Cormont, and V. Hofman, "Helicobacter pylori counteracts the apoptotic action of its VacA toxin by injecting the CagA protein into gastric epithelial cells," PLoS Pathogens, vol. 5, no. 10, article e1000603, 2009.

[190] R. H. Argent, R. J. Thomas, D. P. Letley, M. G. Rittig, K. R. Hardie, and J. C. Atherton, "Functional association between the Helicobacter pylori virulence factors VacA and CagA," Journal of Medical Microbiology, vol. 57, no. 2, pp. 145-150, 2008.

[191] N. Tegtmeyer, D. Zabler, D. Schmidt, R. Hartig, S. Brandt, and S. Backert, "Importance of EGF receptor, HER2/Neu and Erk1/2 kinase signalling for host cell elongation and scattering induced by the Helicobacter pylori CagA protein: antagonistic effects of the vacuolating cytotoxin VacA," Cellular Microbiology, vol. 11, no. 3, pp. 488-505, 2009.

[192] H. Lu, P.-I. Hsu, D. Y. Graham, and Y. Yamaoka, "Duodenal ulcer promoting gene of Helicobacter pylori," Gastroenterology, vol. 128, no. 4, pp. 833-848, 2005.

[193] N. R. Hussein, R. H. Argent, C. K. Marx, S. R. Patel, K. Robinson, and J. C. Atherton, "Helicobacter pylori dupA is polymorphic, and its active form induces proinflammatory cytokine secretion by mononuclear cells," Journal of Infectious Diseases, vol. 202, no. 2, pp. 261-269, 2010.

[194] Y. Yamaoka, T. Kodama, O. Gutierrez, J. G. Kim, K. Kashima, and D. Y. Graham, "Relationship between Helicobacter priori iceA, cagA, and vacA status and clinical outcome: studies in four different countries," Journal of Clinical Microbiology, vol. 37, no. 7, pp. 2274-2279, 1999.

[195] C. Figueiredo, W. G. V. Quint, and R. Sanna, "Genetic organization and heterogeneity of the iceA locus of Helicobacter pylori," Gene, vol. 246, no. 1-2, pp. 59-68, 2000.

[196] Q. Xu, R. D. Morgan, R. J. Roberts et al., "Functional analysis of iceA1, a CATG-recognizing restriction endonuclease gene in Helicobacter pylori," Nucleic Acids Research, vol. 30, no. 17, pp. 3839-3847, 2002.

[197] R. M. Peek, S. A. Thompson, J. P. Donahue et al., "Adherence to gastric epithelial cells induces expression of a Helicobacter pylori gene, iceA, that is associated with clinical outcome," Proceedings of the Association of American Physicians, vol. 110, no. 6, pp. 531-544, 1998.

[198] Y. Yamaoka, S. Kikuchi, H. M. T. ElZimaity, O. Gutierrez, M. S. Osato, and D. Y. Graham, "Importance of Helicobacter pylori OipA in clinical presentation, gastric inflammation, and mucosal interleukin 8 production," Gastroenterology, vol. 123, no. 2, pp. 414-424, 2002.

[199] F. H. Tabassam, D. Y. Graham, and Y. Yamaoka, "OipA plays a role in Helicobacter pylori-induced focal adhesion kinase activation and cytoskeletal re-organization," Cellular Microbiology, vol. 10, no. 4, pp. 1008-1020, 2008.

[200] J. Calam, "Helicobacter pylori modulation of gastric acid," Yale Journal of Biology and Medicine, vol. 72, no. 2-3, pp. 195202, 1999.
[201] E. M. El-Omar, M. Carrington, and W. H. Chow, "The role of interleukin-1 polymorphisms in the pathogenesis of gastric cancer.," Nature, vol. 412, no. 6842, p. 99, 2001.

[202] E. M. El-Omar, C. S. Rabkin, M. D. Gammon et al., "Increased risk of noncardia gastric cancer associated with proinflammatory cytokine gene polymorphisms," Gastroenterology, vol. 124, no. 5, pp. 1193-1201, 2003.

[203] T. Furuta, N. Shirai, F. Xiao et al., "Polymorphism of interleukin- $1 \beta$ affects the eradication rates of Helicobacter pylori by triple therapy," Clinical Gastroenterology and Hepatology, vol. 2, no. 1, pp. 22-30, 2004.

[204] I. R. Hwang, P. I. Hsu, and L. E. Peterson, "Interleukin6 genetic polymorphisms are not related to Helicobacter pylori-associated gastroduodenal diseases," Helicobacter, vol. 8, no. 2, pp. 142-148, 2003.

[205] J. C. Machado, C. Figueiredo, P. Canedo et al., "A proinflammatory genetic profile increases the risk for chronic atrophic gastritis and gastric carcinoma," Gastroenterology, vol. 125, no. 2, pp. 364-371, 2003.

[206] R. Rad, C. Prinz, B. Neu et al., "Synergistic effect of Helicobacter pylori virulence factors and interleukin-1 polymorphisms for the development of severe histological changes in the gastric mucosa," Journal of Infectious Diseases, vol. 188, no. 2, pp. 272-281, 2003.

[207] C. F. Zambon, D. Basso, F. Navaglia et al., "Helicobacter pylori virulence genes and host IL-1RN and IL- $1 \beta$ genes interplay in favouring the development of peptic ulcer and intestinal metaplasia," Cytokine, vol. 18, no. 5, pp. 242-251, 2002.

[208] T. Suzuki, E. Grand, and C. Bowman, "TNF- $\alpha$ and interleukin 1 activate gastrin gene expression via MAPK- and PKC-dependent mechanisms," American Journal of Physiology Gastrointestinal and Liver Physiology, vol. 281, no. 6, pp. G1405-G1412, 2001.

[209] E. J. Yoo, S. Y. Park, and N. Y. Cho, "Influence of IL1B polymorphism on CpG island hypermethylation in Helicobacter pylori-infected gastric cancer," Virchows Archiv, vol. 456, no. 6, pp. 647-652, 2010.

[210] I. Ohyama, N. Ohmiya, Y. Niwa et al., "The association between tumour necrosis factor- $\alpha$ gene polymorphism and the susceptibility to rugal hyperplastic gastritis and gastric carcinoma," European Journal of Gastroenterology and Hepatology, vol. 16, no. 7, pp. 693-700, 2004.

[211] S. S. Yea, Y. I. Yang, W. H. Jang, Y. J. Lee, H. S. Bae, and K. H. Paik, "Association between TNF- $\alpha$ promoter polymorphism and Helicobacter pylori cagA subtype infection," Journal of Clinical Pathology, vol. 54, no. 9, pp. 703-706, 2001.

[212] N. Hamajima, N. Katsuda, K. Matsuo et al., "High antiHelicobacter pylori antibody seropositivity associated with the combination of IL-8-251TT and IL-10-819TT genotypes," Helicobacter, vol. 8, no. 2, pp. 105-110, 2003.

[213] S. Hellmig, J. Hampe, U. R. Fölsch, and S. Schreiber, "Role of IL-10 promoter haplotypes in Helicobacter pylori associated gastric inflammation," Gut, vol. 54, no. 6, p. 888, 2005.

[214] C. F. Zambon, D. Basso, F. Navaglia et al., "Pro- and anti-inflammatory cytokines gene polymorphisms and Helicobacter pylori infection: interactions influence outcome," Cytokine, vol. 29, no. 4, pp. 141-152, 2005.

[215] R. Rad, A. Dossumbekova, and B. Neu, "Cytokine gene polymorphisms influence mucosal cytokine expression, gastric inflammation, and host specific colonisation during Helicobacter pylori infection," Gut, vol. 53, no. 8, pp. 10821089, 2004. 
[216] M. T. H. Ng, R. Van’t Hof, and J. C. Crockett, "Increase in $\mathrm{NF}-\kappa \mathrm{B}$ binding affinity of the variant $\mathrm{C}$ allele of the tolllike receptor $9-1237 \mathrm{~T} / \mathrm{C}$ polymorphism is associated with Helicobacter pylori-induced gastric disease," Infection and Immunity, vol. 78, no. 3, pp. 1345-1352, 2010.

[217] P. Hofner, Z. Gyulai, Z. F. Kiss et al., "Genetic polymorphisms of NOD1 and IL-8, but not polymorphisms of TLR4 genes, are associated with Helicobacter pylori-induced duodenal ulcer and gastritis," Helicobacter, vol. 12, no. 2, pp. 124-131, 2007.

[218] M. Macarthur, G. L. Hold, and E. M. El-Omar, "Inflammation and Cancer II. Role of chronic inflammation and cytokine gene polymorphisms in the pathogenesis of gastrointestinal malignancy," American Journal of Physiology Gastrointestinal and Liver Physiology, vol. 286, no. 4, pp. G515-G520, 2004.

[219] S. Eidt, M. Stolte, and R. Fischer, "Helicobacter pylori gastritis and primary gastric non-Hodgkin's lymphomas," Journal of Clinical Pathology, vol. 47, no. 5, pp. 436-439, 1994.

[220] J. Parsonnet and P. G. Isaacson, "Bacterial infection and MALT lymphoma," New England Journal of Medicine, vol. 350, no. 3, pp. 213-215, 2004.

[221] A. De Mascarel, A. Ruskone-Fourmestraux, A. LavergneSlove, F. Megraud, P. Dubus, and J. P. Merlio, "Clinical, histological and molecular follow-up of 60 patients with gastric marginal zone lymphoma of mucosa-associated lymphoid tissue," Virchows Archiv, vol. 446, no. 3, pp. 219-224, 2005.

[222] W. Fischbach, M. E. Goebeler-Kolve, B. Dragosics, A. Greiner, and M. Stolte, "Long term outcome of patients with gastric marginal zone B cell lymphoma of mucosa associated lymphoid tissue (MALT) following exclusive Helicobacter pylori eradication therapy: experience from a large prospective series," Gut, vol. 53, no. 1, pp. 34-37, 2004.

[223] S. Nakamura, T. Matsumoto, H. Suekane et al., "Longterm clinical outcome of Helicobacter pylori eradication for gastric mucosa-associated lymphoid tissue lymphoma with a reference to second-line treatment," Cancer, vol. 104, no. 3, pp. 532-540, 2005.

[224] T. Wündisch, C. Thiede, A. Morgner et al., "Long-term follow-up of gastric MALT lymphoma after Helicobacter pylori eradication," Journal of Clinical Oncology, vol. 23, no. 31, pp. 8018-8024, 2005.

[225] M. Raderer, B. Streubel, S. Woehrer et al., "High relapse rate in patients with MALT lymphoma warrants lifelong followup," Clinical Cancer Research, vol. 11, no. 9, pp. 3349-3352, 2005.

[226] H. Liu, H. Ye, and A. RuskoneFourmestraux, " $\mathrm{T}(11 ; 18)$ is a marker for all stage gastric MALT lymphomas that will not respond to H. pylori eradication," Gastroenterology, vol. 122, no. 5, pp. 1286-1294, 2002.

[227] H. Inagaki, T. Nakamura, C. Li et al., "Gastric MALT lymphomas are divided into three groups based on responsiveness to Helicobacter pylori eradication and detection of API2-MALT1 fusion," American Journal of Surgical Pathology, vol. 28, no. 12, pp. 1560-1567, 2004.

[228] P. Malfertheiner, F. Megraud, C. O’Morain et al., "Current concepts in the management of Helicobacter pylori infection: the Maastricht III Consensus Report," Gut, vol. 56, no. 6, pp. 772-781, 2007.

[229] B. F. M. Werdmuller and R. J. L. F. Loffeld, "Helicobacter pylori infection has no role in the pathogenesis of reflux esophagitis," Digestive Diseases and Sciences, vol. 42, no. 1, pp. 103-105, 1997.
[230] C. A. Fallone, A. N. Barkun, M. U. Göttke et al., "Association of Helicobacter pylori genotype with gastroesophageal reflux disease and other upper gastrointestinal diseases," American Journal of Gastroenterology, vol. 95, no. 3, pp. 659-669, 2000.

[231] R. Befrits, S. Sjöstedt, B. Ödman, H. Sörngård, and G. Lindberg, "Curing Helicobacter pylori infection in patients with duodenal ulcer does not provoke gastroesophageal reflux disease," Helicobacter, vol. 5, no. 4, pp. 202-205, 2000.

[232] E. M. El-Omar, K. Oien, A. El-Nujumi et al., "Helicobacter pylori infection and chronic gastric acid hyposecretion," Gastroenterology, vol. 113, no. 1, pp. 15-24, 1997.

[233] N. Vakil, B. Hahn, and D. McSorley, "Recurrent symptoms and gastro-oesophageal reflux disease in patients with duodenal ulcer treated for Helicobacter pylori infection," Alimentary Pharmacology and Therapeutics, vol. 14, no. 1, pp. 45-51, 2000.

[234] A. Gasbarrini, F. Franceschi, R. Tartaglione, R. Landolfi, P. Pola, and G. Gasbarrini, "Regression of autoimmune thrombocytopenia after eradication of Helicobacter pylori," Lancet, vol. 352, no. 9131, p. 878, 1998.

[235] G. Emilia, M. Luppi, P. Zucchini et al., "Helicobacter pylori infection and chronic immune thrombocytopenic purpura: long-term results of bacterium eradication and association with bacterium virulence profiles," Blood, vol. 110, no. 12, pp. 3833-3841, 2007.

[236] A. Asahi, M. Kuwana, H. Suzuki, T. Hibi, Y. Kawakami, and Y. Ikeda, "Effects of a Helicobacter pylori eradication regimen on anti-platelet autoantibody response in infected and uninfected patients with idiopathic thrombocytopenic purpura," Haematologica, vol. 91, no. 10, pp. 1436-1437, 2006.

[237] M. Kodama, Y. Kitadai, M. Ito et al., "Immune response to CagA protein is associated with improved platelet count after Helicobacter pylori eradication in patients with idiopathic thrombocytopenic purpura," Helicobacter, vol. 12, no. 1, pp. 36-42, 2007.

[238] C. Hershko, M. Ianculovich, and M. Souroujon, "A hematologist's view of unexplained iron deficiency anemia in males: impact of Helicobacter pylori eradication," Blood Cells, Molecules and Diseases, vol. 38, no. 1, pp. 45-53, 2007.

[239] Y. Chen and M. J. Blaser, "Inverse associations of Helicobacter pylori with asthma and allergy," Archives of Internal Medicine, vol. 167, no. 8, pp. 821-827, 2007.

[240] O. Herbarth, M. Bauer, G. J. Fritz et al., "Helicobacter pylori colonisation and eczema," Journal of Epidemiology and Community Health, vol. 61, no. 7, pp. 638-640, 2007.

[241] F. Cremonini and A. Gasbarrini, "Atopy, Helicobacter pylori and the hygiene hypothesis," European Journal of Gastroenterology and Hepatology, vol. 15, no. 6, pp. 635-636, 2003.

[242] M. Kist, "Helicobacter pylori: primary antimicrobial resistance and first-line treatment strategies," Eurosurveillance, vol. 12, no. 7, pp. E1-2, 2007.

[243] N. Wueppenhorst, H. P. Stueger, M. Kist, and E. Glocker, "Identification and molecular characterization of triple- and quadruple-resistant Helicobacter pylori clinical isolates in Germany," Journal of Antimicrobial Chemotherapy, vol. 63, no. 4, pp. 648-653, 2009.

[244] P. F. Saldinger, N. Porta, P. Launois et al., "Immunization of $\mathrm{BALB} / \mathrm{c}$ mice with Helicobacter urease B induces a T helper 2 response absent in Helicobacter infection," Gastroenterology, vol. 115, no. 4, pp. 891-897, 1998.

[245] T. Aebischer, D. Bumann, H. J. Epple et al., "Correlation of $\mathrm{T}$ cell response and bacterial clearance in human volunteers challenged with Helicobacter pylori revealed by randomised 
controlled vaccination with Ty21a-based Salmonella vaccines," Gut, vol. 57, no. 8, pp. 1065-1072, 2008.

[246] Y. Du, A. Agnew, X.-P. Ye, P. A. Robinson, D. Forman, and J. E. Crabtree, "Helicobacter pylori and Schistosoma japonicum co-infection in a Chinese population: helminth infection alters humoral responses to $\mathrm{H}$. pylori and serum pepsinogen I/II ratio," Microbes and Infection, vol. 8, no. 1, pp. 52-60, 2006.

[247] M. F. Elshal, I. H. Elsayed, and I. M. El Kady, "Role of concurrent S. mansoni infection in $\mathrm{H}$. pylori-associated gastritis: a flow cytometric DNA-analysis and oxyradicals correlations," Clinica Chimica Acta, vol. 346, no. 2, pp. 191198, 2004.

[248] G. L. Lorca, T. Wadström, G. Font de Valdez, and Å Ljungh, "Lactobacillus acidophilus autolysins inhibit Helicobacter pylori in vitro," Current Microbiology, vol. 42, no. 1, pp. 3944, 2001.

[249] P. D. Midolo, J. R. Lambert, R. Hull, F. Luo, and M. L. Grayson, "In vitro inhibition of Helicobacter pylori NCTC 11637 by organic acids and lactic acid bacteria," Journal of Applied Bacteriology, vol. 79, no. 4, pp. 475-479, 1995.

[250] I. Sakamoto, M. Igarashi, K. Kimura, A. Takagi, T. Miwa, and Y. Koga, "Suppressive effect of Lactobacillus gasseri OLL 2716 (LG21) on Helicobacter pylori infection in humans," Journal of Antimicrobial Chemotherapy, vol. 47, no. 5, pp. 709-710, 2001.

[251] J. Zou, J. Dong, and X. Yu, "Meta-analysis: lactobacillus containing quadruple therapy versus standard triple first-line therapy for Helicobacter pylori eradication," Helicobacter, vol. 14, no. 5, pp. 97-107, 2009. 


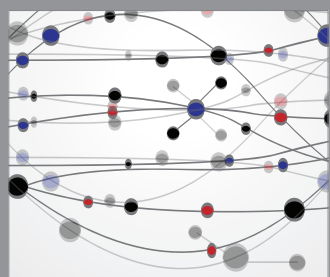

The Scientific World Journal
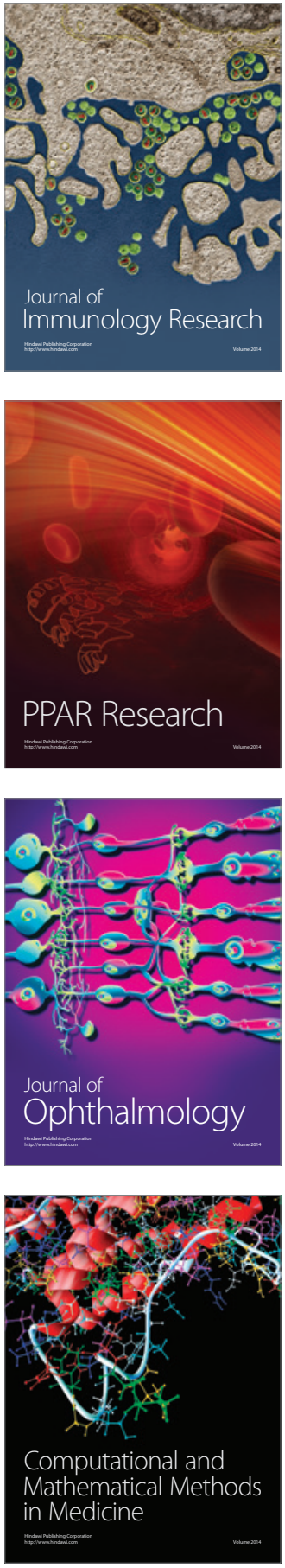

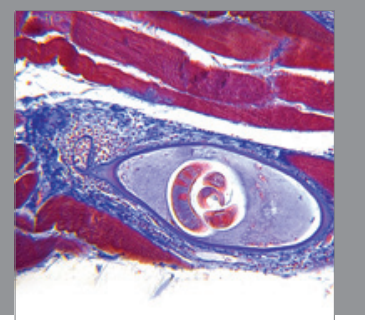

Gastroenterology

Research and Practice
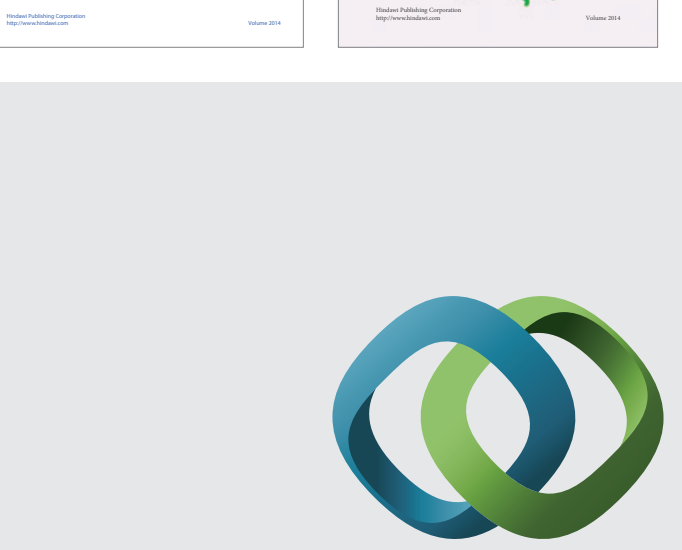

\section{Hindawi}

Submit your manuscripts at

http://www.hindawi.com
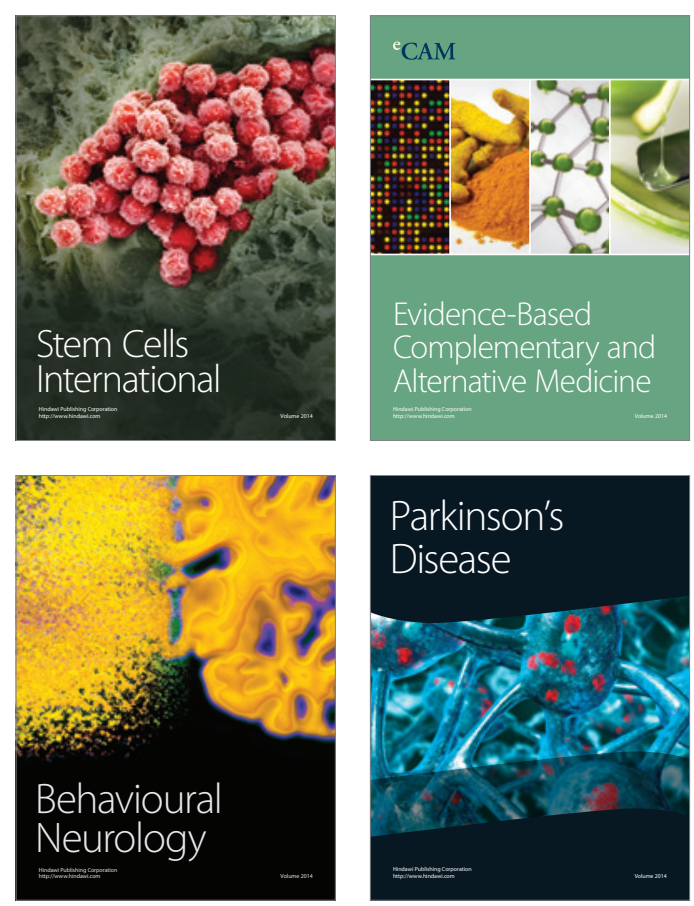

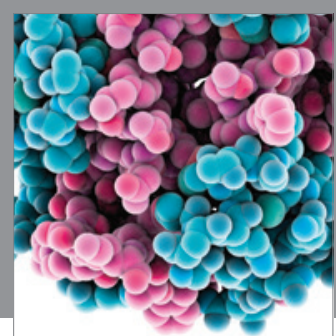

Journal of
Diabetes Research

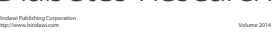

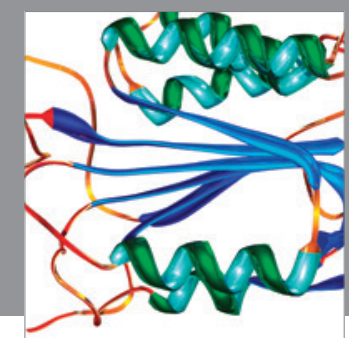

Disease Markers
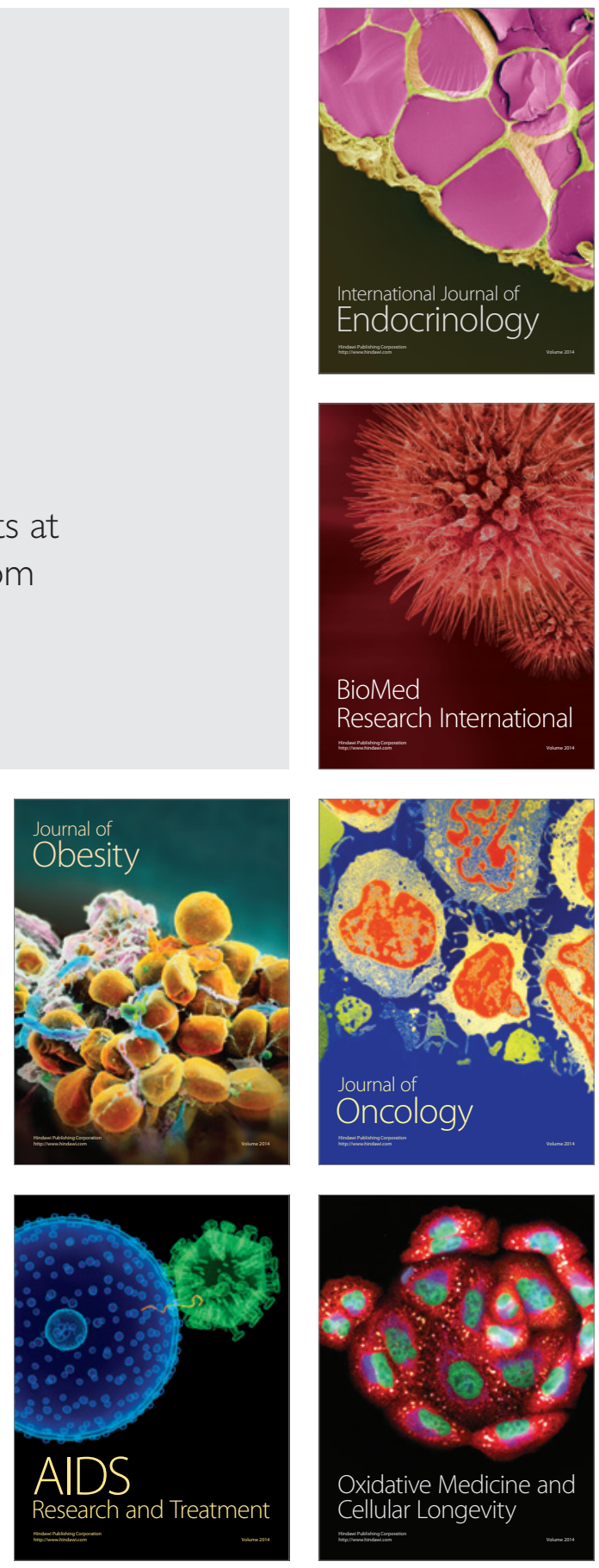